\title{
Intraseasonal and Interannual Variability of Extreme Dry and Wet Events over Southeastern South America and the Subtropical Atlantic during Austral Summer
}

\author{
MiCHEL N. MUZA \\ Department of Atmospheric Sciences, University of São Paulo, São Paulo, Brazil \\ LeILA M. V. CARVALHO \\ Department of Atmospheric Sciences, University of São Paulo, São Paulo, Brazil, and Institute for Computational \\ Earth System Sciences, University of California, Santa Barbara, Santa Barbara, California \\ CHARLES JONES \\ Institute for Computational Earth System Sciences, University of California, Santa Barbara, Santa Barbara, California \\ BRANT LIEBMANN \\ CIRES Climate Diagnostics Center, Boulder, Colorado
}

(Manuscript received 26 November 2007, in final form 9 October 2008)

\begin{abstract}
Intraseasonal and interannual variability of extreme wet and dry anomalies over southeastern Brazil and the western subtropical South Atlantic Ocean are investigated. Precipitation data are obtained from the Global Precipitation Climatology Project (GPCP) in pentads during 23 austral summers (December-February 1979/ 80-2001/02). Extreme wet (dry) events are defined according to 75th (25th) percentiles of precipitation anomaly distributions observed in two time scales: intraseasonal and interannual. The agreement between the 25th and 75th percentiles of the GPCP precipitation and gridded precipitation obtained from stations in Brazil is also examined. Variations of extreme wet and dry anomalies on interannual time scales are investigated along with variations of sea surface temperature (SST) and circulation anomalies. The South Atlantic SST dipole seems related to interannual variations of extreme precipitation events over southeastern Brazil. It is shown that extreme wet and dry events in the continental portion of the South Atlantic convergence zone (SACZ) are decoupled from extremes over the oceanic portion of the SACZ and there is no coherent dipole of extreme precipitation regimes between tropics and subtropics on interannual time scales. On intraseasonal time scales, the occurrence of extreme dry and wet events depends on the propagation phase of extratropical wave trains and consequent intensification (weakening) of 200-hPa zonal winds. Extreme wet and dry events over southeastern Brazil and subtropical Atlantic are in phase on intraseasonal time scales. Extreme wet events over southeastern Brazil and subtropical Atlantic are observed in association with low-level northerly winds above the 75th percentile of the seasonal climatology over central-eastern South America. Extreme wet events on intraseasonal time scales over southeastern Brazil are more frequent during seasons not classified as extreme wet or dry on interannual time scales.
\end{abstract}

\section{Introduction}

The wet season in most of tropical and subtropical South America peaks in the austral summer, typically

\footnotetext{
Corresponding author address: Michel Nobre Muza, Department of Atmospheric Sciences, University of São Paulo, 1226, R. do Matão, São Paulo, SP 05508-900 Brazil.

E-mail: michelnm@model.iag.usp.br
}

from December to February (e.g., Liebmann and Marengo 2001; Marengo et al. 2001). The South Atlantic convergence zone (SACZ) is the most prominent largescale feature of cloudiness and precipitation in the wet season of eastern tropical South America. It can be observed as a northwest-southeast-oriented cloud band emanating from the Amazon basin toward southeastern Brazil and the western subtropical South Atlantic Ocean (Kodama 1993; Liebmann et al. 1999; Nogués-Paegle 
and Mo 1997; Lenters and Cook 1999; Carvalho et al. 2002a, 2004). Nevertheless, SACZ persistence, intensity, and form are quite variable during the summer season (Figueroa et al. 1995; Carvalho et al. 2002a, 2004). These quantities, which are related to distinct aspects of the large-scale circulation, define the spatial and temporal variation of rainfall and its extremes (Liebmann et al. 2001, 2004; Carvalho et al. 2002a,b,c, 2004) and therefore the characteristics of the South America monsoon system (Zhou and Lau 1998; Jones and Carvalho 2002; Grimm 2003; Vera et al. 2006; Silva and Carvalho 2007.

Variations in the SACZ have been observed on intraseasonal to interannual time scales. For instance, Liebmann et al. (2001), using a large number of station data over the state of São Paulo (southeastern Brazil), showed that the count of extreme daily precipitation events increases during warm El Niño-Southern Oscillation (ENSO) episodes. Carvalho et al. (2002a) showed that the most significant increase of extreme precipitation events during El Niño years occurs near the northeastern coast of São Paulo state, which is likely related to an enhancement of the upper-level subtropical jet and its displacement toward the western subtropical Atlantic. This anomalous circulation appears to be associated with the intensification of the oceanic portion of the SACZ (Carvalho et al. 2002a, 2004). Moreover, Carvalho et al. (2004) showed that a persistent SACZ with a well-defined oceanic (continental) activity is favored during warm (cold) ENSO episodes.

Several previous studies have shown that the large-scale flow from the Amazon is likely the main mechanism maintaining the SACZ position (e.g., Figueroa et al. 1995; Nogués-Paegle and Mo 1997; Liebmann et al. 2004; Gan et al. 2004). The most coherent forcing of SACZ variability seems to be intraseasonal and synoptic-scale midlatitude wave trains (e.g., Liebmann et al. 1999; Carvalho et al. 2004). Casarin and Kousky (1986) analyzed anomalous episodes in southern Brazil and found that anomalously dry conditions in that region are associated with a weak SACZ. Nogués-Paegle and Mo (1997) found a quasi oscillation in the intensification of rainfall in SACZ with half period of about 10 days, which was referred to as the South American seesaw. Similar results were found by Liebmann et al. (1999) and Carvalho et al. (2004). Nevertheless, Carvalho et al. (2004) showed that the seesaw does not appear when convection in the SACZ is weak over the ocean and strong over the continent. Their results indicate, however, that the extratropical wave train is the main forcing mechanism for the enhancement of convection over the subtropical western Atlantic Ocean and coastal areas of southeastern South America on intraseasonal time scales (Grimm and Silva Dias 1995; Liebmann et al. 1999; Nogués-Paegle et al. 2000).
The occurrence of extreme precipitation over tropical South America is modulated by the propagation of the Madden-Julian oscillation (MJO). Carvalho et al. (2004) showed that the phase of the MJO as characterized by anomalous convection east of the international date line (over Indonesia) is related to an enhancement (decrease) of convective activity and a consequent increase (decrease) in the 95th percentile of daily rainfall over eastern Brazil. These results suggest a role of the MJO in modifying the characteristics of the rainfall distributions and, therefore, modulating precipitation extremes.

Jones et al. (2004) investigated eastward propagation of the MJO and occurrences of 5-day average extreme precipitation on a global scale. They showed that, globally, extreme precipitation events increase by about $40 \%$ during active MJO situations. They found also that extremes become more frequent in southern Brazil and the tropical Atlantic Ocean when convective anomalies over Indonesia propagate eastward. In contrast, extremes in a broad region over eastern South America and tropical Atlantic are more frequent during the phase of the MJO characterized by convective anomalies over the central Pacific.

As the MJO propagates eastward across the equatorial Pacific, it excites midlatitude wave trains, playing a role in modulating the intensity and spatial variability of convection over tropical and subtropical South America. Intense (weak) convective activity in the SACZ on intraseasonal time scales (10-100 days) appears related to westerly (easterly) intraseasonal anomalies of the lowlevel circulation over central South America (Jones and Carvalho 2002; Carvalho et al. 2002b,c, 2004). Interestingly, Liebmann et al. (2004) showed that the phase of the wave train, as it crosses the Andes, determines whether rainfall will be enhanced downstream of the Andes at the low-level jet or in the SACZ.

The focus of the present study is on the variability of extreme wet and dry periods over southeastern Brazil and the oceanic portion of the SACZ. Southeastern South America comprises the most populated area in South America and is considered an important agricultural center. A broader understanding of possible mechanisms related to variations in extreme rainfall anomalies have, therefore, relevant social and economic impacts for this region. In the present study, extreme wet and dry anomalies will be examined in two distinct time scales: intraseasonal and interannual. The purposes of this separation of scales are the following: 1) investigate atmospheric mechanisms responsible for the occurrence of extremes that are coherent on the examined time scale, 2) characterize extreme precipitation and dry periods in the SACZ and their relationships with the seesaw 
pattern between southeastern and southern Brazil on interannual time scales, and 3) understand the contribution of the intraseasonal activity to interannual variability of extreme wet/dry anomalies.

This article is organized as follows: section 2 discusses the dataset used in this study. In section 3, we discuss the seasonal spectral variance of precipitation data, compare the Global Precipitation Climatology Project (GPCP) data in the regions of interest with gridded precipitation obtained from stations over Brazil and discuss the method to select extreme precipitation/dry events on intraseasonal and interannual time scales. Composites of extreme precipitation, SST, and the atmospheric circulation on interannual time scales are investigated in section 4. Atmospheric mechanisms associated with the occurrence of intraseasonal extremes are discussed in section 5 . The relationships between extremes on intraseasonal and interannual time scales over southeastern South America and oceanic SACZ regions are examined in section 6. Summary and conclusions are presented in section 7 .

\section{Data}

The precipitation data are 5-day mean (pentad) rainfall from GPCP. The GPCP pentad is based on station gauges and satellite estimates with spatial resolution $2.5^{\circ} \times 2.5^{\circ}$ in latitude and longitude. The period investigated here is the austral summer (DecemberFebruary) from 1979/80 to 2001/02 (Xie et al. 2003). The advantage of using GPCP pentad data is that there is coverage over the ocean, which opens the possibility of investigating precipitation extremes in association with the oceanic portion of the SACZ.

Circulation patterns and SST anomalies are examined with pentad averages of National Centers for Environmental Prediction-National Center for Atmospheric Research (NCEP-NCAR) reanalysis (Kalnay et al. 1996) of the following variables: zonal (U850) and meridional winds at $850 \mathrm{hPa}$ (V850), zonal winds at $200 \mathrm{hPa}$ (U200), and skin temperature. The latter was used as a proxy for global SST. Outgoing longwave radiation (OLR) data (Liebmann and Smith 1996) in pentads with the same spatial resolution as the reanalysis are also used.

\section{Methods}

We start our study by examining the power spectrum of GPGP data during December-February (DJF) over two regions that enclose the following areas: southeastern Brazil $\left(25^{\circ}-15^{\circ} \mathrm{S}\right.$ and $\left.52.5^{\circ}-42.5^{\circ} \mathrm{W}\right)$ and western subtropical South Atlantic $\left(35^{\circ}-25^{\circ} \mathrm{S}\right.$ and $\left.42.5^{\circ}-32.5^{\circ} \mathrm{W}\right)$. The objective of this analysis is to identify the intraseasonal bands that contain most of the variance. Figure 1 shows
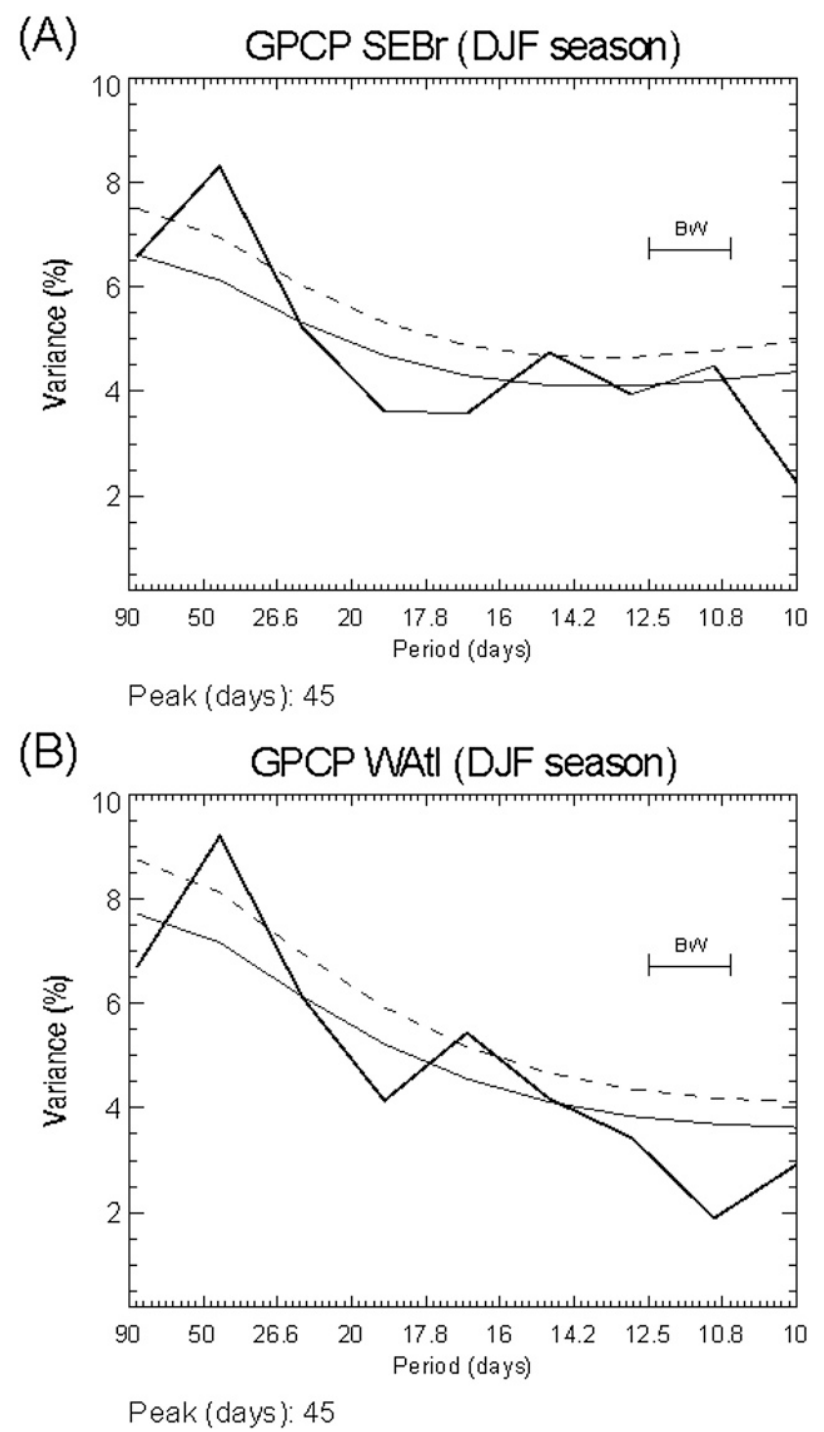

FIG. 1. Average spectrum of GPCP during the DJF season over (a) southeastern Brazil (SEBr: $22.5^{\circ}-12.5^{\circ} \mathrm{S}$ and $\left.52.5^{\circ}-42.5^{\circ} \mathrm{W}\right)$ and (b) subtropical western South Atlantic (WAtl: $32.5^{\circ}-22.5^{\circ} \mathrm{S}$ and $42.5^{\circ}-32.5^{\circ} \mathrm{W}$ ). Period: $1979-2004$. Smooth solid line represents the background red noise spectrum and dashed line is the $95 \%$ significance level. The bandwidth (BW) is indicated on the top right corner of the frames.

the average spectra of 24 DJF seasons (for more details see Jones et al. 1998). Statistically significant peaks on intraseasonal time scales between 66.6 and 33.3 days (52.6 and 36.4 days) are observed for the seasonal precipitation over SEBr (WAtl). Due to 5-day average (pentad), variations on scales less than $\sim 10$ days are not resolved. Based on the spectral analysis, intraseasonal (20-90 days) anomalies were obtained by filtering all precipitation time series in frequency domain with fast Fourier transform (FFT; e.g., Carvalho et al. 2005). The 
frequency response of FFT filter is approximately 50\% on the cutoff periods. For this reason, a 20-90-day band is used because it is wider than the statistically significant peaks shown in Fig. 1. Likewise, interannual anomalies (hereafter referred to as "low frequency") were obtained by applying the same filter in the frequency domain and retaining periods $>370$ days.

Standard deviations of intraseasonal and low-frequency anomalies of precipitation during DJF over South America are shown in Fig. 2. The SACZ can be clearly observed in Fig. 2a as a region with a large standard deviation of precipitation on intraseasonal time scales during summer over eastern South America and extending toward the Atlantic Ocean (Carvalho et al. 2004) with a gap between the maxima over the continent and the Atlantic Ocean.

The maximum variability on low-frequency time scales (Fig. 2b), on the other hand, is observed over the northern coast of Brazil, Colombia, and Ecuador in association with the intertropical convergence zone (ITCZ). Another maximum on low-frequency time scales is observed over southern Brazil, approximately collocated with the maximum observed on intraseasonal time scales. ENSO is the most important forcing on interannual time scales and is largely responsible for the pattern of precipitation variability on low-frequency time scales over tropical and southern Brazil, Uruguay, and northeastern Argentina (e.g., Ropelewski and Halpert 1987; Karoly 1989; Kousky and Kayano 1994; Grimm 2003).

The domains examined in this study correspond to the regions of maximum variability of precipitation on intraseasonal time scales over southeastern South America and the subtropical Atlantic Ocean (e.g., Nogués-Paegle and Mo 1997; Liebmann et al. 1999; Carvalho et al. 2004), which correspond approximately to the climatological position of the SACZ.

\section{a. Comparison between GPCP and gridded station data}

The GPCP rainfall estimates were compared with gridded precipitation data at the same $2.5^{\circ} \times 2.5^{\circ}$ resolution obtained from stations in Brazil [Department of Water and Electric Energy (DAEE) and National Agency for Electric Energy (ANEEL)] from 1979 to 1998. Details of the gridded precipitation dataset are discussed in Liebmann and Allured (2005). To compare the two sources of data, average precipitations from GPCP estimates and from gridded precipitation (hereafter gauges) were computed over SEBr for all DJF pentads. For SEBr (Fig. 2a), the correlation between the datasets is 0.91 , while the bias $\left[=(1 / n) \sum_{t=1}^{n}\left(\mathrm{GPCP}_{t}-\right.\right.$

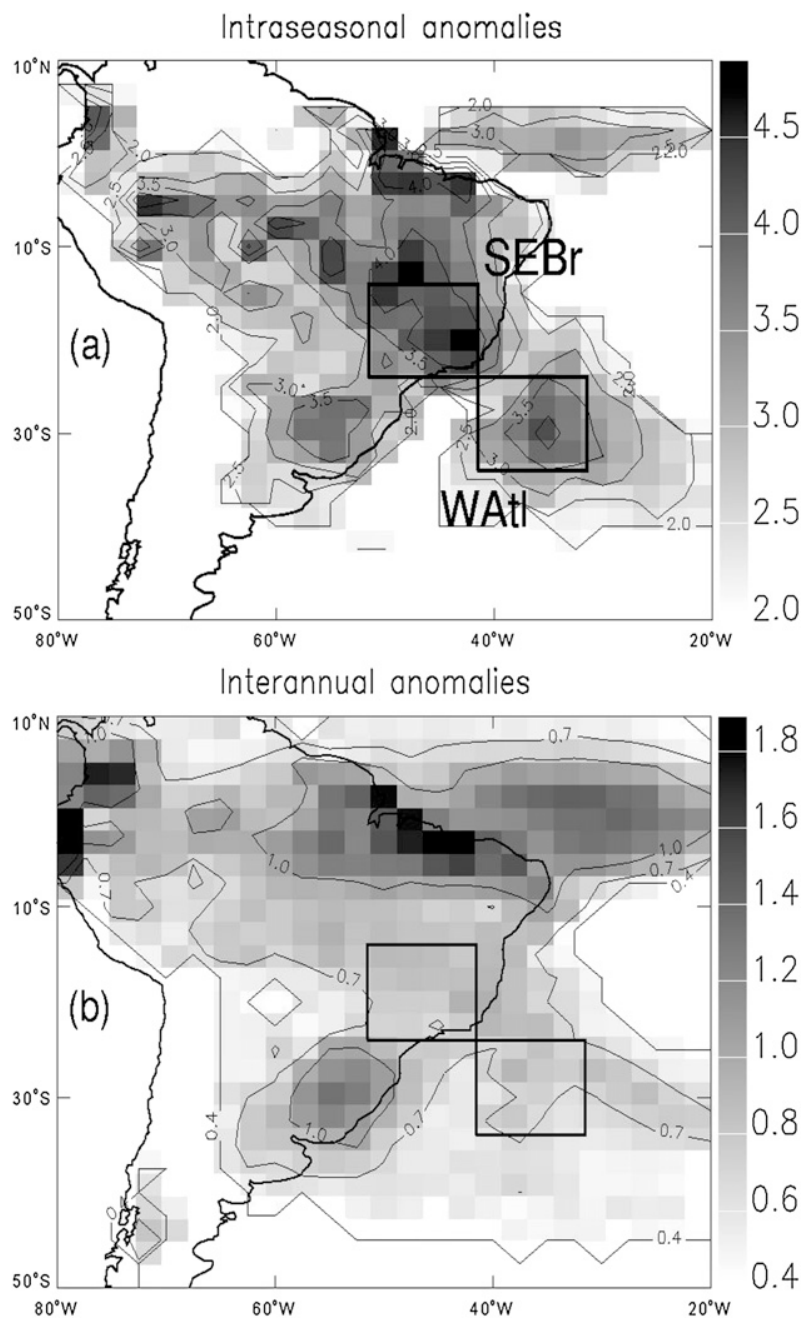

FIG. 2. (a) Intraseasonal (interval $2-5 \mathrm{~mm} \mathrm{day}^{-1}$ ) and (b) lowfrequency (interval $0.4-1 \mathrm{~mm} \mathrm{day}^{-1}$, ) standard deviation of precipitation (shaded) $\left(\mathrm{mm} \mathrm{day}^{-1}\right)$. The reference regions for composites are indicated by boxes.

gauges $\left._{t}\right)$ ] is $0.16 \mathrm{~mm} \mathrm{day}^{-1}$ and the root-mean-square difference $\left\{=\left[(1 / n) \sum_{t=1}^{n}\left(\mathrm{GPCP}_{t}-\text { gauges }_{t}\right)^{2}\right]^{1 / 2}\right\}$ is 1.16 $\mathrm{mm}$ day $^{-1}$. The close correspondence between the two datasets warrants the use of GPCP data in this study.

We note, however, that probability distribution functions of precipitation are, in general, skewed. To objectively investigate the relationships between the two datasets with respect to extreme precipitation, percentiles that characterize the tails of the precipitation distributions were compared. For this purpose, the gamma distribution (Wilks 1995) was fitted to the precipitation time series of each individual dataset (e.g., Ropelewski and Halpert 1987; Grimm 2003) and the 5th, 25th, 50th, 75th, and 95th percentiles were then computed. While the mean bias between the two datasets is small (Fig. 3a), we observe a relative difference 
(a)

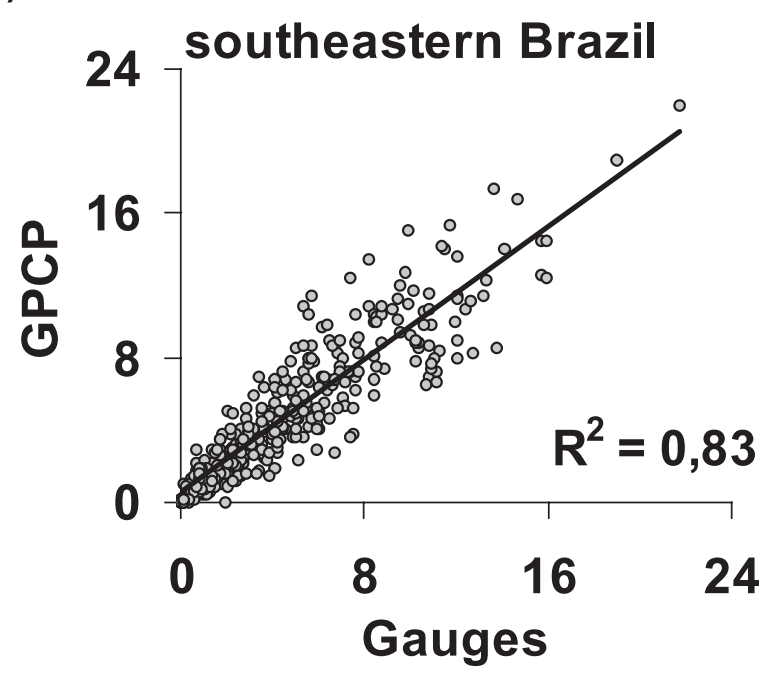

(b)

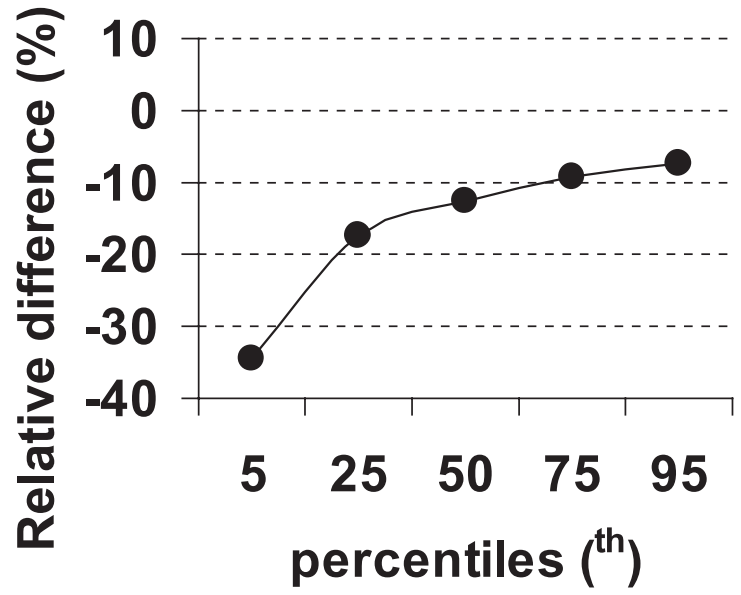

FIG. 3. Dispersion diagram between GPCP and gridded precipitation obtained from stations $\left(\mathrm{mm} \mathrm{day}^{-1}\right)$ for (a) SEBr and (b) relative difference (\%) between GPCP and gridded precipitation according to the percentiles of the distribution (abscissa). See text for details.

$[=($ GPCP - gauges $) /$ gauges $]$ of about $-11 \%$ between the medians (Fig. 3b). Nevertheless, GPCP approaches gauges for large percentiles, whereas differences increase for small percentiles. For example, the relative difference is about $-8 \%$ for the 95 th percentile, whereas it is about $-35 \%$ for the 5 th percentile (Fig. 3b).

\section{b. Selection of events}

Extreme precipitation (dry period) is defined according to 75 th (25th) percentile of the precipitation anomaly distributions observed on intraseasonal and low-frequency time scales. Extreme precipitation (dry) events are selected when more than $50 \%$ of the 25 total grid points in each domain had anomalies above (be- low) the 75th (25th) percentile. Persistence of wet and dry extreme events is also examined. Persistence is defined as the number of consecutive pentads recording extreme precipitation/dry events. Figure 4 shows the median, upper, and lower quartiles; interquartile range; outliers (persistence $>2$ times the interquartile range); and nonoutlier maximum and minimum of persistence of events on intraseasonal and low-frequency time scales. On intraseasonal time scales the median persistence and upper quartiles for both extreme wet and dry events is 2 pentads. The maximum (nonoutlier) range is 4 pentads and minimum is 1 pentad.

On low-frequency time scales, the median persistence of extreme wet anomalies is 12 pentads, lower quartile 9 pentads, and upper quartile 17 pentads. It is interesting to note that the interquartile range of persistence of dry extreme events is comparatively small, with median 11 pentads, lower quartile 6 pentads, and upper quartile 12 pentads, indicating that wet anomalies can last longer than dry anomalies. In this study we examined extreme wet and dry events on intraseasonal and low-frequency time scales that persisted for two or more pentads. The number of independent events (degrees of freedom) for all statistical tests performed here was determined based on the persistence of extreme events. On intraseasonal (low-frequency) time scales, we consider as independent events those events that are separated by two or more pentads (one season).

\section{Wet and dry events on low-frequency time scales}

In this section we examine spatial characteristics of low-frequency precipitation anomalies during wet and dry episodes with a focus on the regions shown in Fig. 2. For this purpose, composites were computed by averaging the anomalies observed during extreme events. Wet low-frequency anomalies over SEBr are related to positive precipitation anomalies throughout tropical eastern South America as well as Indonesia and negative anomalies over central equatorial Pacific (Fig. 5a). It is interesting, however, that dry conditions over $\mathrm{SEBr}$ (Fig. 5b) also favor positive anomalies over northnortheast South America in association with an active Atlantic ITCZ, and negative anomalies over the equatorial Pacific. Negative anomalies in the equatorial $\mathrm{Pa}-$ cific are of larger scale than those associated with positive SEBr anomalies (Fig. 5a). In addition, an area with positive anomalies is observed over Indonesia extending toward the South Pacific convergence zone (SPCZ) in the dry events composite (Fig. 5b). This feature is absent when $\mathrm{SEBr}$ experiences positive extremes (Fig. $5 a)$. The precipitation anomaly patterns over the tropics suggest that dry and wet events over $\mathrm{SEBr}$ are not 


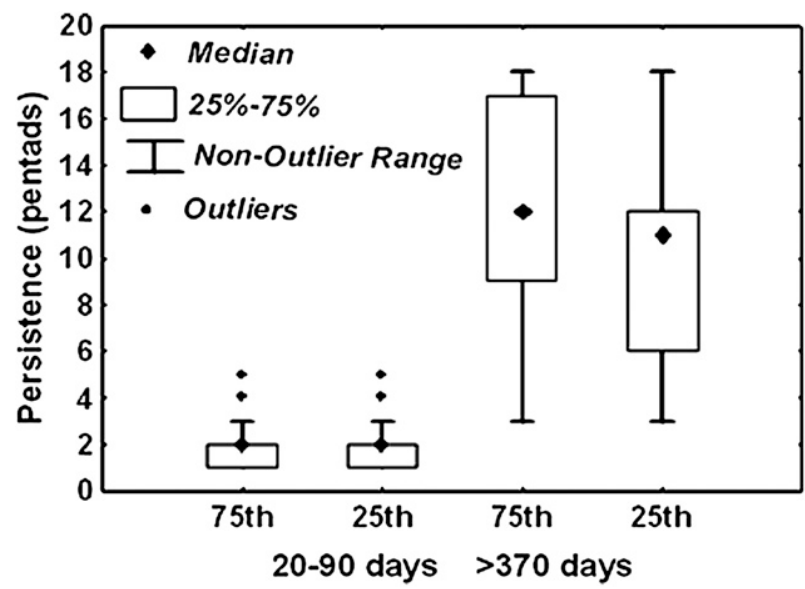

FIG. 4. Box-plot diagram illustrating the median, upper, lower quartiles and the interquartile range of the distributions of persistence of extreme dry and wet events on (left) intraseasonal and (right) low-frequency time scales for all regions. The limits of the boxes represent the interquartile range. Outliers are data values $\geq 2$ times the interquartile range.

clearly related to phases of ENSO, as both positive and negative extremes are associated with negative anomalies in the equatorial Pacific.

Low-frequency extremes over the western subtropical South Atlantic (WAtl; Figs. 5c,d) are characterized by anomalies of smaller magnitude and scale than those over the continent previously discussed. No coherent signal of precipitation anomalies is observed over continental South America during extreme dry or wet events in that region. In addition, the patterns of precipitation over the Atlantic and Pacific Oceans differ from those observed for wet or dry events over SEBr (cf. Figs. 5a,b) and do not resemble the canonical patterns of precipitation related to ENSO. Only $32 \%$ (38\%) of the total pentads associated with extreme wet (dry) anomalies over WAtl occurred simultaneously with wet (dry) events over SEBr. These results suggest that distinct mechanisms modulate the variability of extreme precipitation over the oceanic portion of the SACZ and the continental SAZC, in agreement with previous observations (Carvalho et al. 2002a, 2004).

\section{a. Sea surface temperature}

The characteristics of SST low-frequency anomalies $\left(\mathrm{SST}_{\mathrm{LF}}\right)$ associated with patterns of extreme dry and wet events previously discussed are examined here. Consistent with the pattern of precipitation anomalies, extreme wet and dry events over SEBr are both related to negative $\mathrm{SST}_{\mathrm{LF}}$ anomalies over the eastern Pacific (Figs. 6a,b). Dry events over SEBr do not exhibit a reversal in the sign of the $\mathrm{SST}_{\mathrm{LF}}$ anomalies over eastern Pacific (cf. Fig. 6a). Nonetheless, relatively large mag- nitudes and westward extension of negative $\mathrm{SST}_{\mathrm{LF}}$ anomalies are observed during dry events (Fig. 6b). Three out of six dry events occurred during cold phases, and two during neutral ENSO phases. ENSO phases and intensity are based on the NCEP/Climate Prediction Center classification.

Another interesting feature of the $\mathrm{SST}_{\mathrm{LF}}$ is observed over the South Atlantic Ocean, where extremes are associated with opposite phases of the South Atlantic SST dipole (Robertson and Mechoso 2000). Wet (dry) extreme events over $\mathrm{SEBr}$ occur when the $\mathrm{SST}_{\mathrm{LF}}$ anomalies gradient over the South Atlantic is southward (northward). Extreme wet (Fig. 6c) and dry (Fig. 6d) events over WAtl seem also related to distinct $\mathrm{SST}_{\mathrm{LF}}$ gradients over the Atlantic Ocean. However, there are no systematic relationships with low-frequency extreme precipitation anomalies over SEBr.

\section{b. Upper-level circulation}

Kodama $(1992,1993)$ suggested that the SACZ, similar to other subtropical convergence zones, appears when two necessary conditions in midlatitude circulation are satisfied: first, subtropical jet flows in the subtropical latitudes $\left(30^{\circ}-35^{\circ} \mathrm{S}\right)$ and second, low-level poleward flows prevail along the western peripheries of the subtropical highs. It has been postulated that if these conditions are not satisfied, the convergence zone is weak. It is important to point out that Kodama focused mainly on the oceanic portion of the SACZ. The objective of the present analysis is to investigate the importance of low-frequency anomalies in low- and high-level circulations along with variations in the Pacific-South American (PSA) pattern (Mo and Nogués-Paegle 2001) for the occurrence of extreme wet/dry events over the regions considered here. For this purpose zonal wind low-frequency anomalies at $200 \mathrm{hPa}\left(\mathrm{U} 200_{\mathrm{LF}}\right)$ and wind low-frequency anomalies at $850 \mathrm{hPa}\left(\mathrm{UV} 850_{\mathrm{LF}}\right)$ during extreme wet and dry events on low-frequency time scales are examined.

Figure 7 shows that extreme wet (dry) events in all regions are observed in association with a local enhancement of U200 ${ }_{\mathrm{LF}}$ westerly (easterly) anomalies. The PSA pattern characterized by the alternating U200 ${ }_{\mathrm{LF}}$ anomalies over western South America is evident during wet events over SEBr (Fig. 7a). Dry episodes over SEBr, on the other hand, are characterized by a large extent of easterly anomalies over large portions of the tropics of the Southern Hemisphere (Fig. 7b). Westerly anomalies are observed over the equator between $180^{\circ}$ and $120^{\circ} \mathrm{W}$ and also over the extratropics of the Southern Hemisphere, indicating an intensification of the zonal symmetry in high-level circulation.

Composites of U200 $0_{\mathrm{LF}}$ show clear evidence that the occurrence of extreme wet (Fig. 7c) and dry (Fig. 7d) 

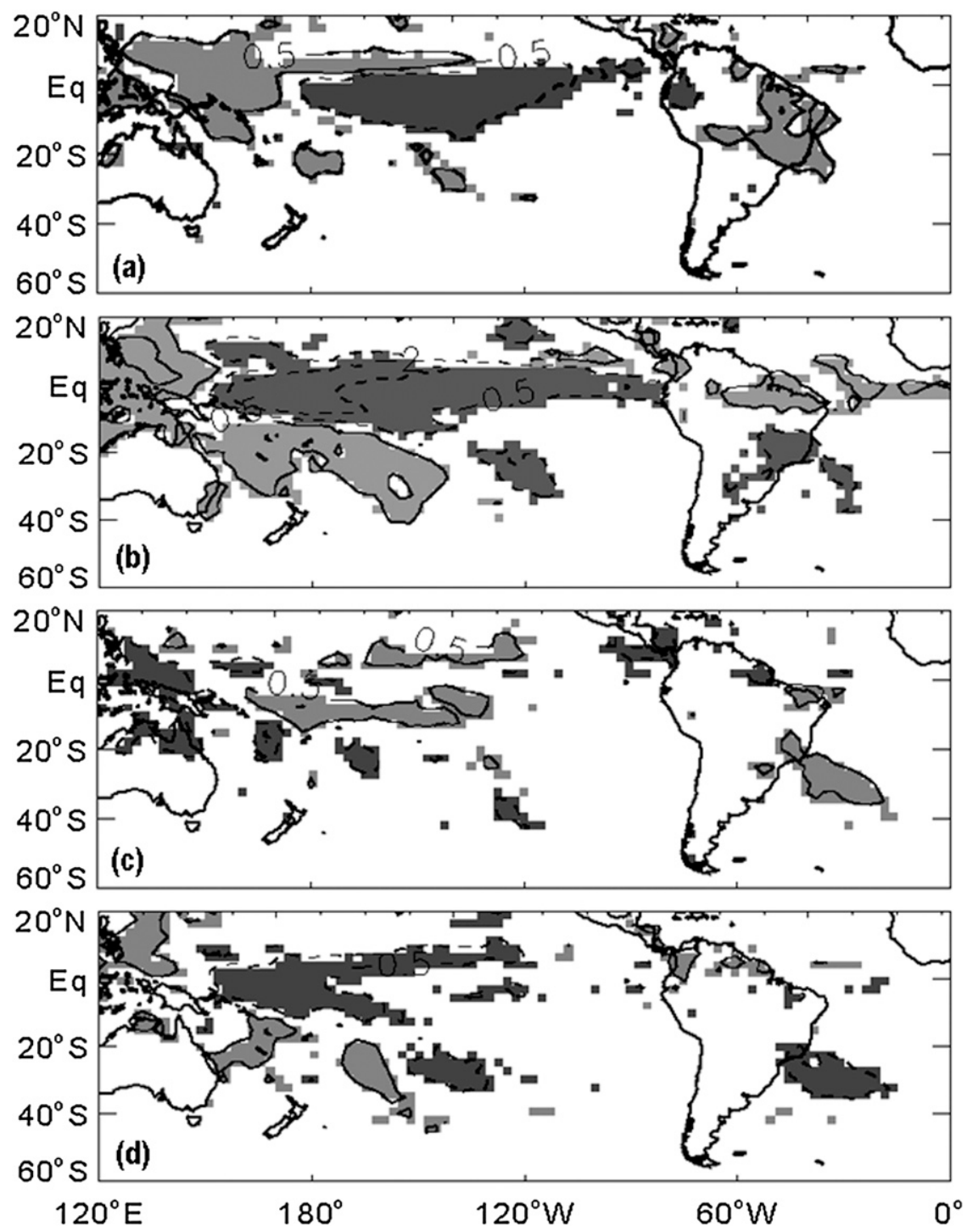

FIG. 5. Composites of GPCP low-frequency anomalies $\left(\mathrm{mm} \mathrm{day}^{-1}\right)$ for wet and dry extreme events, respectively: (a), (b) SEBr; (c), (d) WAtl. Shading indicates statistical significance at 95\% confidence level. Light (dark) shading and solid (dashed) contours indicate positive (negative) anomalies. First contour is $0.5(-0.5)$ and second is $2.0(-2.0)$ with interval 2.0.

events over WAtl are not dynamically forced by the same mechanisms during extreme events over SEBr on low-frequency time scales. Positive U200 ${ }_{\mathrm{LF}}$ anomalies are less intense and cover a small area in the subtropics during wet events (Fig. 7c), but indicate the importance of the enhancement of the jet over the oceanic SACZ. Dry events (Fig. 7d) show opposite patterns of U200 ${ }_{\mathrm{LF}}$ anomalies with a weak subtropical jet in the Southern Hemisphere.

\section{c. Low-level circulation}

Patterns of low-level wind circulation anomaly at 850 $\mathrm{hPa}\left(\mathrm{UV} 850_{\mathrm{LF}}\right)$ are shown in Fig. 8. Wet extreme events over $\mathrm{SEBr}$ are associated with anomalous anticyclonic circulation over central-eastern Brazil (Fig. 8a). This anomalous circulation increases the northerly winds from equatorial Atlantic across northern South America and intensifies the westerlies over tropical Brazil. As a consequence, the transport of humidity toward southeastern Brazil increases and is likely related to the enhancement of precipitation in the SACZ. On the other hand, dry events on low-frequency time scales over SEBr occur in association with cyclonic anomalies over eastern South America (Fig. 8b). In these cases, zonal westerly anomalies are observed near the equator and easterly anomalies over eastern South America. 

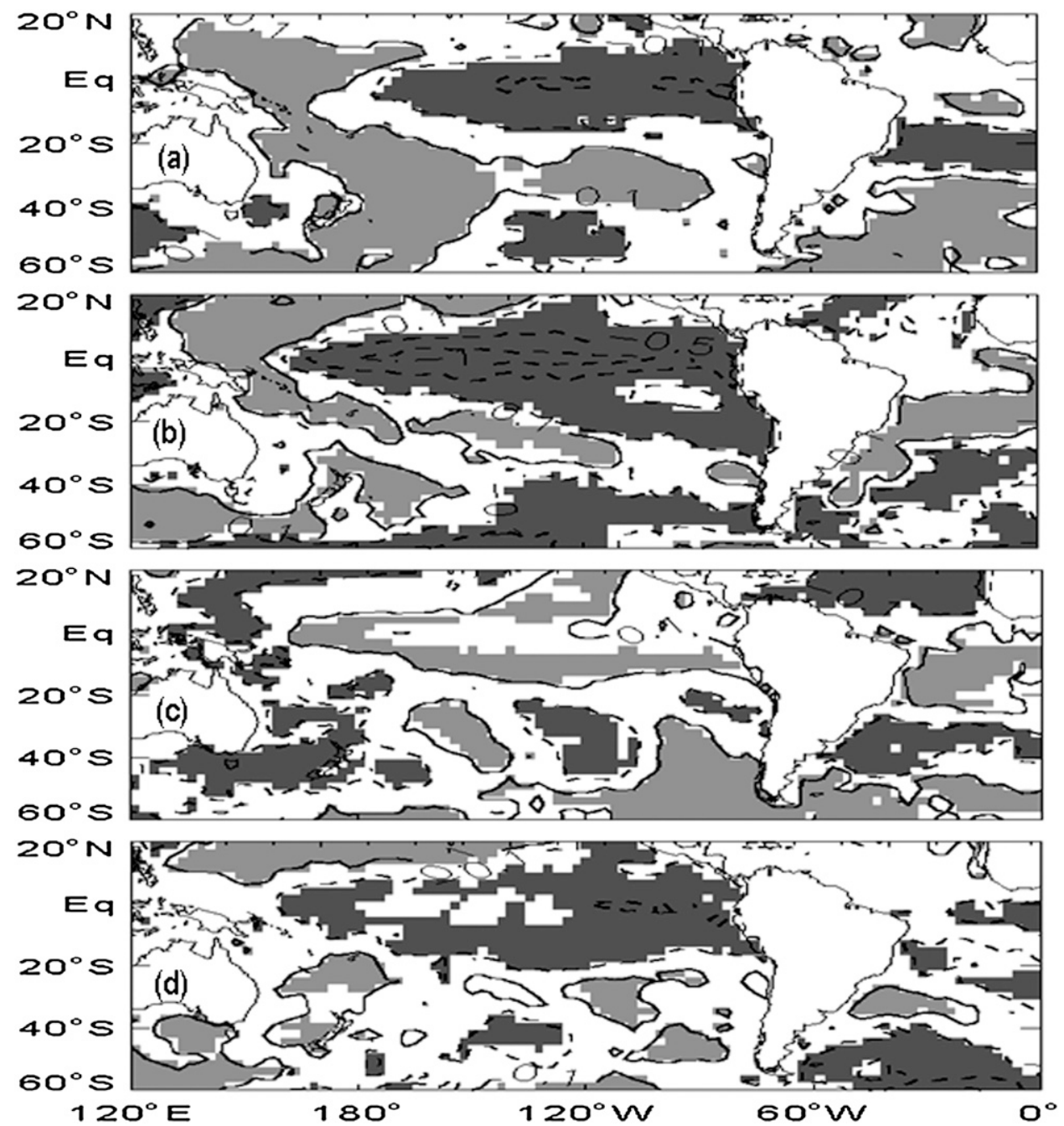

FIG. 6. Same as in Fig. 5, but for SST (>370 days) low frequency. First contour is $0.1^{\circ} \mathrm{C}\left(-0.1^{\circ} \mathrm{C}\right)$ and second is $0.5^{\circ} \mathrm{C}\left(-0.5^{\circ} \mathrm{C}\right)$ with interval $0.5^{\circ} \mathrm{C}$.

Easterly anomalies over tropical South America inhibit the transport of humidity from the Amazon and have been related to a weak SACZ (Herdies et al. 2002; Carvalho et al. 2002a; Jones and Carvalho 2002).

The existence of distinct mechanisms modulating extreme precipitation over WAtl and SEBr on lowfrequency time scales is also suggested by the pattern of UV850 $_{\text {LF }}$ (Fig. 8). Wet events over WAtl (Fig. 8c) are observed along with the enhancement of a cyclonic anomaly over the subtropical western Atlantic, with a center $\sim 40^{\circ} \mathrm{W}$ and $40^{\circ} \mathrm{S}$. This anomalous circulation is associated with southerly anomalies over subtropical South America, extending from the midlatitudes of the western Atlantic toward central tropical South America and to the equator. This pattern of circulation anomalies clearly differs from that observed during wet events over SEBr (Fig. 8a), a region that typically corresponds to the continental portion of the SACZ (Carvalho et al. 2004). The most remarkable difference is the almost opposite anomalous flow from the equatorial Atlantic across the Amazon toward southeastern Brazil. Westerly wind anomalies occur over a much narrower region eastern of South America, in comparison with SEBr (Fig. 8a). Nonetheless, this pattern of low-level circulation suggests that the poleward flow discussed in Kodama (1993) occurs north (equatorward) of WAtl above warm SST (Fig. 6c), and is collocated with increased high-level westerly wind anomalies (Fig. 7c). In addition, equatorward low-level flow occurs south (poleward) of WAtl above cold SST (Fig. 6d). These are important ingredients to maintain low-level convergence and therefore enhance precipitation over WAtl.

Dry events over WAt are clearly associated with the enhancement of the subtropical Atlantic anticyclone 
(a)

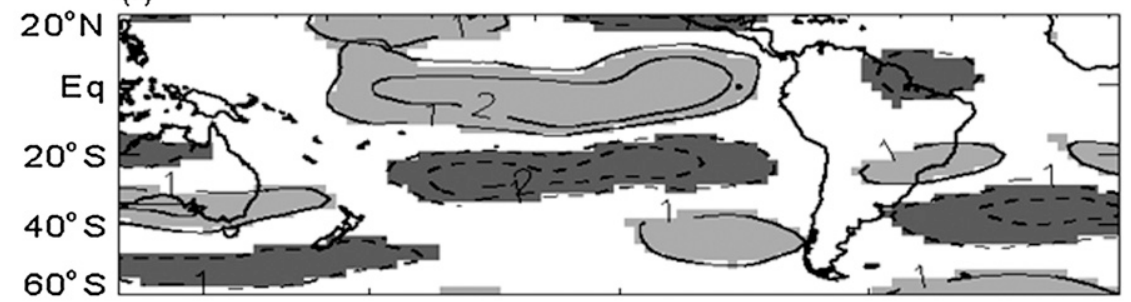

(b)

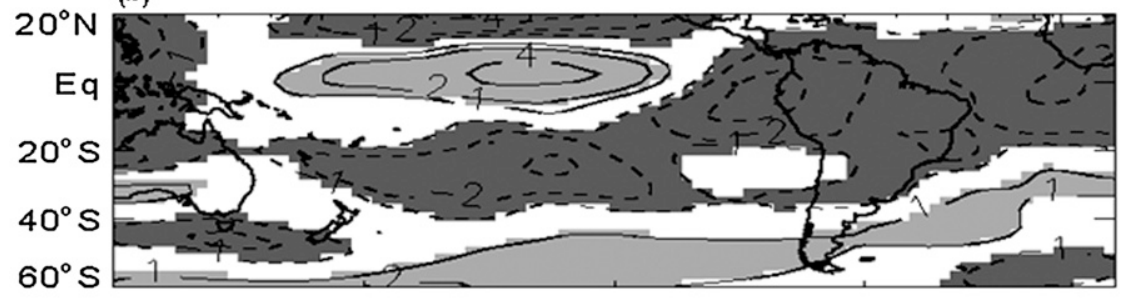

(c)

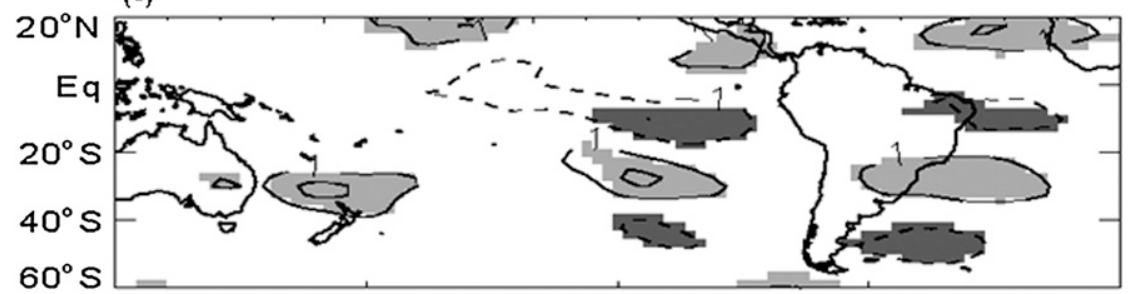

(d)

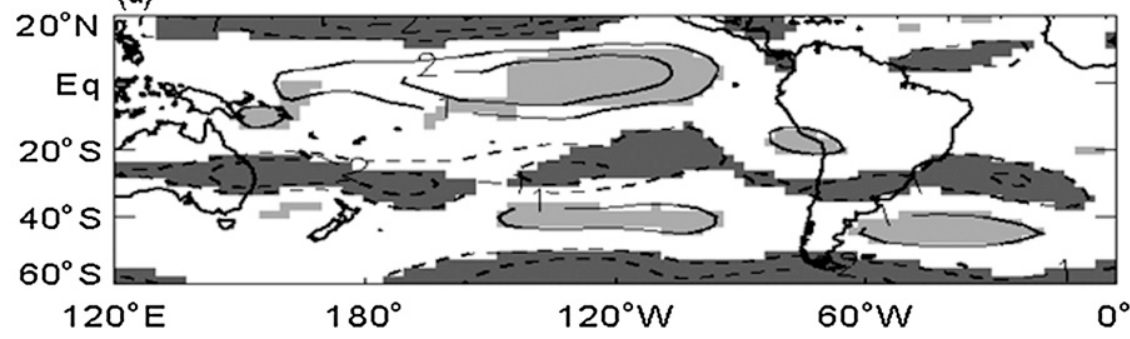

FIG. 7. Same as in Fig. 5, but for composites of 200-hPa zonal wind $\left(\mathrm{m} \mathrm{s}^{-1}\right)$. First contour is $1.0 \mathrm{~m} \mathrm{~s}^{-1}$ $\left(-1.0 \mathrm{~m} \mathrm{~s}^{-1}\right)$ and second is $2.0 \mathrm{~m} \mathrm{~s}^{-1}\left(-2.0 \mathrm{~m} \mathrm{~s}^{-1}\right)$ with interval $2.0 \mathrm{~m} \mathrm{~s}^{-1}$.

(Fig. 8d). The center of this anomaly is located approximately at $30^{\circ} \mathrm{S}$ and is associated with easterly anomalies over SEBr and northerly anomalies over south Brazil. An intensification of the poleward flow occurs south of WAtl whereas the equatorward flow intensifies north of the region collocated with easterly upper-level zonal wind anomalies (Fig. 7e). As postulated by Kodama (1992), these features inhibit the organization of the subtropical convergence zones.

\section{Wet and dry events on intraseasonal time scales}

The objective of this section is to examine in detail the role of the $\mathrm{MJO}$ in modulating extreme precipitation anomalies on intraseasonal time scales. Jones et al. (2004), Carvalho et al. (2004), and Liebmann et al. (2004) provided insights into understanding the role of the MJO in modulating extreme precipitation over broad areas of tropical and subtropical South America. The novelty of the present analysis is the focus on wet and dry intraseasonal anomalies (and not total precipitation) in the region of large intraseasonal variance over South America and the southeastern Atlantic (Fig. 2) and a detailed examination of the relationships of extreme events with the MJO.

Extreme anomalies on intraseasonal time scales are defined as discussed in section $3 \mathrm{~b}$. Figure 9 shows the patterns of wet and dry extreme precipitation anomalies over each region. The striking aspect of the spatial organization of precipitation anomalies on intraseasonal time scales is the seesaw pattern previously documented in some studies (e.g., Casarin and Kousky 

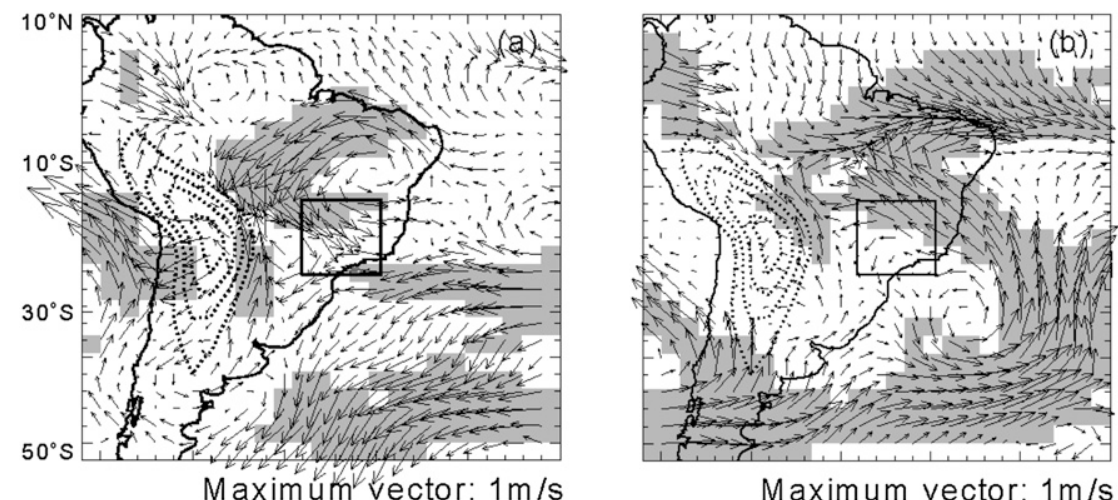

Maximum vector: $1 \mathrm{~m} / \mathrm{s}$
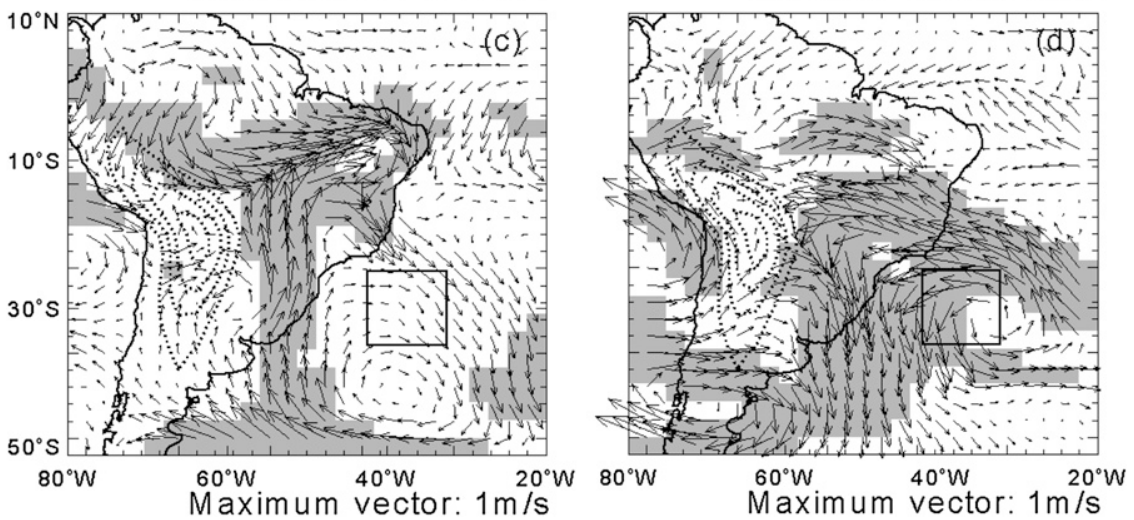

FIG. 8. Composites of 850-hPa wind $\left(\mathrm{m} \mathrm{s}^{-1}\right)$ low-frequency anomalies for (a), (c) wet and (b), (d) dry extreme events: (a), (b) SEBr; (c), (d) WAtl. Shading indicates statistical significance at $95 \%$ confidence level. Boxes show the reference regions for the composites as discussed in the text. Dotted contours show the terrain elevation beginning at $750 \mathrm{~m}$ with $500-\mathrm{m}$ intervals.

1986; Nogués-Paegle and Mo 1997). It is noteworthy, however, that the well-defined seesaw on intraseasonal scales is not evident on low-frequency time scales (cf. with Fig. 5). In addition, Fig. 9 suggests opposite relationships between extreme events over SEBr and southern Brazil (cf. Fig. 9a with Fig. 9b) as part of distinct phases of propagation of the midlatitude wave trains discussed in Liebmann et al. (1999). The seesaw seems also characterized between WAtl and southern Brazil during wet (Fig. 9c) and dry (Fig. 9d) events. About 27\% (29\%) of the extreme wet (dry) pentads over WAtl are observed along with extreme wet (dry) anomalies over SEBr.

\section{a. The Madden-Julian oscillation}

The relationships between the MJO and extremes on intraseasonal time scales in each region are now investigated. To objectively identify the importance of distinct phases of the MJO in modulating precipitation over South America we used the procedure described in Carvalho et al. (2004) and summarized as follows: empirical orthogonal function (EOF) of the outgoing longwave intraseasonal (20-90 days) anomalies $\left(\mathrm{OLR}_{\mathrm{IS}}\right)$ was computed in the domain $15^{\circ} \mathrm{S}-15^{\circ} \mathrm{N}$ (all longitudes)
(1979-2002). The two leading EOF modes characterize the canonical phases of the oscillation over the equatorial Pacific (Weickmann et al. 1985), with the first mode leading the second by two to three pentads (Jones et al. 2004). The patterns of tropical convective intraseasonal anomalies during different phases of propagation of the MJO are indicated from OLR IS $_{\text {compos- }}$ ites obtained when the amplitudes of the time coefficient of the two leading EOFs are above (below) the 75th (25th) percentiles relative to the DJF distribution (Fig. 10).

According to this criterion, the pattern of convective anomalies during the MJO phase characterized by EOF-1 $>$ 75th percentile (Fig. 10a; 31 cases) indicates enhanced convection over the Indian Ocean and suppressed convection over western Pacific Ocean ( $\uparrow$ Indian $\downarrow$ WP), as discussed by Weickmann et al. (1985). In addition, this phase of the MJO is characterized by suppression of convection over eastern tropical South America toward the Atlantic Ocean in agreement with Jones et al. (2004).

The second EOF $($ EOF-2) $<25$ th percentile characterizes the next phase of the MJO (Fig. 10b; 34 cases), 

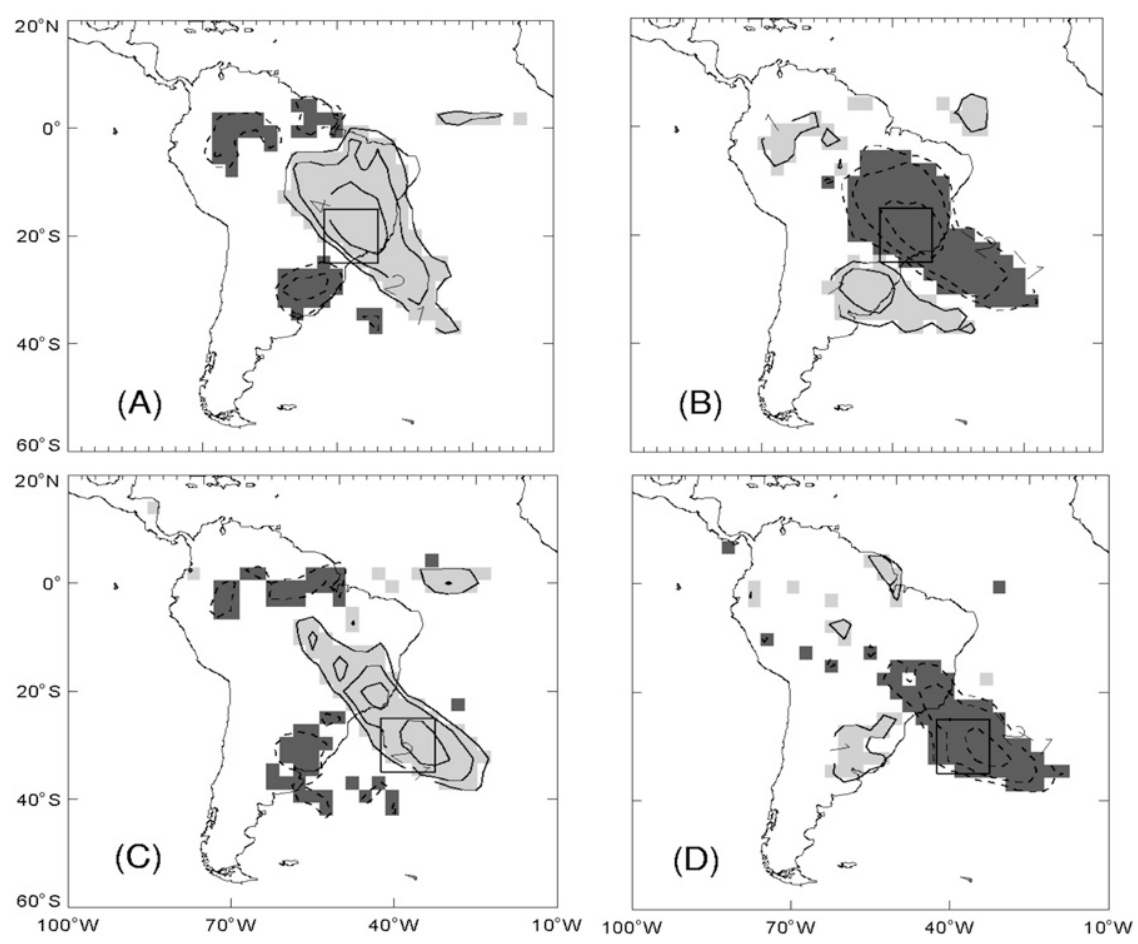

FIG. 9. GPCP intraseasonal (20-90 days) anomalies $\left(\mathrm{mm} \mathrm{day}^{-1}\right)$ during extreme events on intraseasonal time scales for (a), (c) wet and (b), (d) dry extreme events: (a), (b) SEBr; (c), (d) WAtl. First positive (negative) contour is $1.0(-1.0)$ with intervals equal to $2.0 \mathrm{~mm} \mathrm{day}^{-1}$.

when convection is enhanced over Indonesia and suppressed over central Pacific, Africa and eastern tropical South America (SA; $\uparrow$ Indonesia $\downarrow$ SA). Enhancement of convection is observed over southern Brazil, Uruguay, and northern Argentina, extending toward the subtropical Atlantic. The displacement of convection eastward with suppression over the Indian Ocean and enhancement of precipitation over western Pacific (WP; $\downarrow$ Indian $\uparrow \mathrm{WP}$ ) is characterized by EOF-1 $<25$ th percentile (Fig. 10c; 33 cases). As convection moves toward central Pacific and suppression takes place over Indonesia, enhanced convection is observed over eastern South America ( $\downarrow$ Indonesia $\uparrow S A$ ) (Fig. 10d; 36 cases). This phase is characterized by EOF-2 $>75$ th percentile. Note that suppression of convection is also observed over southern Brazil during this phase.

To identify whether extreme events on intraseasonal time scales are modulated by the propagation of the $\mathrm{MJO}$, the frequency of events that were observed in each phase of propagation of the tropical disturbance was computed. Only events that have started during a given phase and have persisted at least two pentads are considered. The results are summarized in Fig. 11. Over SEBr (Fig. 11a), about $50 \%$ of the total wet events (P75) occurred during the $\uparrow \mathrm{SA} \downarrow$ Indonesia MJO phase whereas only $\sim 10 \%$ of the events occurred at other times.
However, the frequency of dry events (P25) is approximately the same during $\uparrow$ Indian $\downarrow$ WP $(35 \%)$ and $\uparrow$ Indonesia $\downarrow$ AS (39\%) phases (Fig. 11a). Nonetheless, fewer than $5 \%$ of the dry events occurred during $\uparrow \mathrm{SA}$ $\downarrow$ Indonesia phase.

Over WAtl (Fig. 11b) $\sim 30 \%$ of the wet events occurred during the $\uparrow \mathrm{WP} \downarrow$ Indian phase against $10 \%$ during $\uparrow$ Indian $\downarrow$ WP. Dry events are relatively more frequent during $\uparrow$ SA $\downarrow$ Indonesia phase $(40 \%)$; nevertheless, all other MJO categories appeared related to frequencies between $15 \%$ and $20 \%$.

A test for the difference of proportions (Spiegel et al. 2000) was applied in order to identify which differences in proportion of extreme events can be considered statistically significant at $5 \%$ significance level. Consider two distinct $\mathrm{MJO}$ phases corresponding to sample sizes equal to $n_{1}$ and $n_{2}$, and $\hat{p}_{1}$ and $\hat{p}_{2}$ are the proportions of extreme events that occurred in each phase as indicated in Fig. 10. To test whether the two proportions can be considered as belonging to distinct populations, the following transformation was applied:

$$
z=\frac{\hat{p}_{1}-\hat{p}_{2}}{\sqrt{\hat{p} \hat{q}\left(1 / n_{1}+1 / n_{2}\right)}}
$$

where $\hat{p}=\left(n_{1} \hat{p}_{1}+n_{2} \hat{p}_{2}\right) /\left(n_{1}+n_{2}\right), \hat{q}=1-\hat{p}$, and $n=$ $n_{1}+n_{2}$. The null hypothesis $H_{0}$ is $p_{1}=p_{2}$ and the 


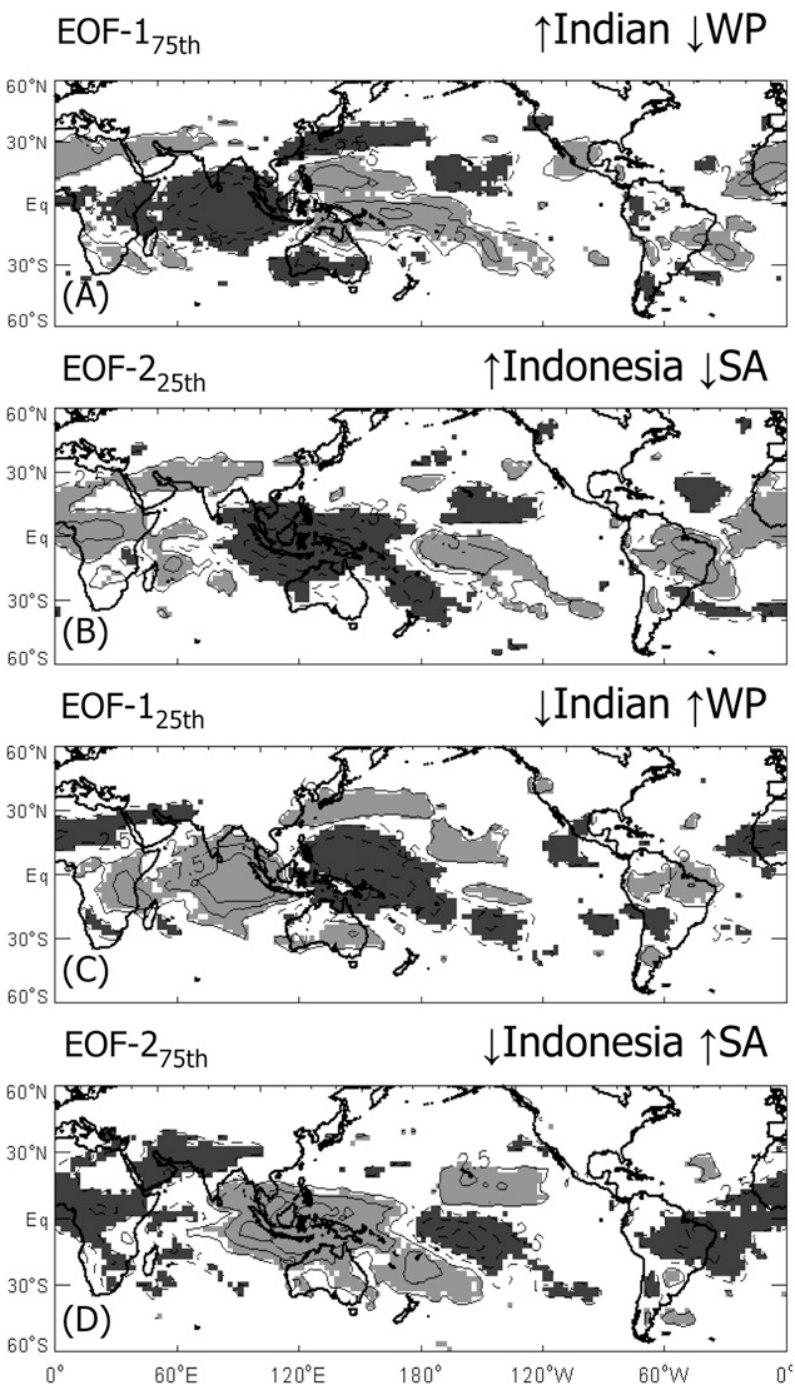

FIG. 10. Composites of OLR intraseasonal anomalies (20-90 days) over the tropics during distinct phases of MJO propagation obtained from the two leading EOF modes of the OLR $\mathrm{IS}_{\mathrm{IS}}$ anomalies between $15^{\circ} \mathrm{S}$ and $15^{\circ} \mathrm{N}$ (see text for details). Composites are performed according to the magnitude of the respective DJF time coefficient using the following criteria: (a) EOF-1 $>75$ th percentile $\left(\right.$ EOF-1 $\left.{ }_{75 \text { th }}\right)$, (b) EOF-2 $<25$ th percentile $($ EOF-2 25 th $)$, (c) EOF-1 $<25$ th $\left(\right.$ EOF-1 ${ }_{25}$ th $)$, and (d) EOF-2 $>75$ th percentile

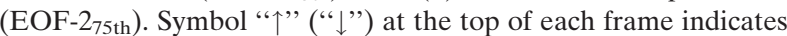
enhancement (weakening) of convective activity in some key regions. Shading indicates statistical significance at $95 \%$ confidence level. Light (dark) shading and solid (dashed) contours indicate positive (negative) anomalies. First positive (negative) contour is $2.5(-2.5)$ and interval $5.0 \mathrm{~W} \mathrm{~m}^{-2}$.

alternative hypothesis $H_{1}$ is $p_{1}>p_{2}$. The $z$ statistics [Eq. (1)] has normal distribution. Statistically significant differences at $5 \%$ level are observed for $z>1.64$. Table 1 summarizes the results. Differences are statistically significant at $5 \%$ significance level for wet events occurring over SEBr during the $\uparrow$ SA $\downarrow$ Indonesia (Fig. 10d) com- pared to all other phases of the MJO. Similarly, dry events over $\mathrm{SEBr}$ are more frequent during $\uparrow$ Indonesia $\downarrow$ AS (Fig. 10b) compared to the opposite phase $\uparrow$ SA $\downarrow$ Indonesia (Fig. 10d) and also with $\uparrow$ WP $\downarrow$ Indian phase (Fig. 10c). Differences are not statistically significant with respect to $\uparrow$ Indian $\downarrow$ WP phase (Fig. 10a) which is associated with similar proportion of dry events.

Differences in the frequency of wet events over WAtl are statistically significant only between $\uparrow \mathrm{WP} \downarrow$ Indian phase (Fig. 10c) and $\uparrow$ Indian $\downarrow$ WP phase (Fig. 10a). The frequency of dry events over WAtl is surprisingly larger during $\uparrow$ SA $\downarrow$ Indonesia (Fig. 10d) compared to $\uparrow$ Indian $\downarrow$ WP phase (Fig. 10a) and $\uparrow$ Indonesia $\downarrow$ AS (Fig. 10b). The WAtl region is located south of the maximum signal of OLR intraseasonal anomalies observed during $\uparrow$ SA $\downarrow$ Indonesia (Fig. 10d). The relationships with MJO phases indicated here are likely the effect in low- and high-level circulations because of equatorial Kelvin and extratropical Rossby response of the MJO (Ferranti et al. 1990; Liebmann et al. 2004).

\section{b. Intraseasonal extreme events and low-level meridional circulation}

Liebmann et al. (2004) investigated the influence of the South American low-level jet east of the Andes on daily precipitation downstream of the jet and in the SACZ. They found that the amount of precipitation approximately doubles its expected climatology when the jet is strong, with evolution of rainfall from south to north. They also showed that the intensification of the jet is related to the development of a baroclinic system farther south. In addition they showed that phases of the MJO have statistically significant amplitudes associated with rainfall both downstream of the jet and in the SACZ. The objective of the present study is to complement Liebmann et al. (2004) study by identifying the relationships between extreme precipitation on intraseasonal time scales and low-level meridional circulation over South America and western South Atlantic. For this purpose, composites of nonfiltered $850-\mathrm{hPa}$ wind during extreme wet and dry events on intraseasonal time scales for each region discussed before were performed (Fig. 12). In addition, for each composite the average meridional wind $(\bar{V})$ was compared with the expected DFJ climatology. Lines in Fig. 12 denote regions where $\bar{V}$ is significantly (5\% two-sided $t$ test) above (continuous lines) and below (dashed lines) the climatological median.

During extreme wet events over SEBr (Fig. 12a), meridional winds $\geq 75$ th percentile of the climatology are observed over eastern South America, north of the $\mathrm{SEBr}$ region, extending toward the Atlantic Ocean. Magnitudes of $\bar{V}$ above the median are also observed 
(a)

southeastern Brazil

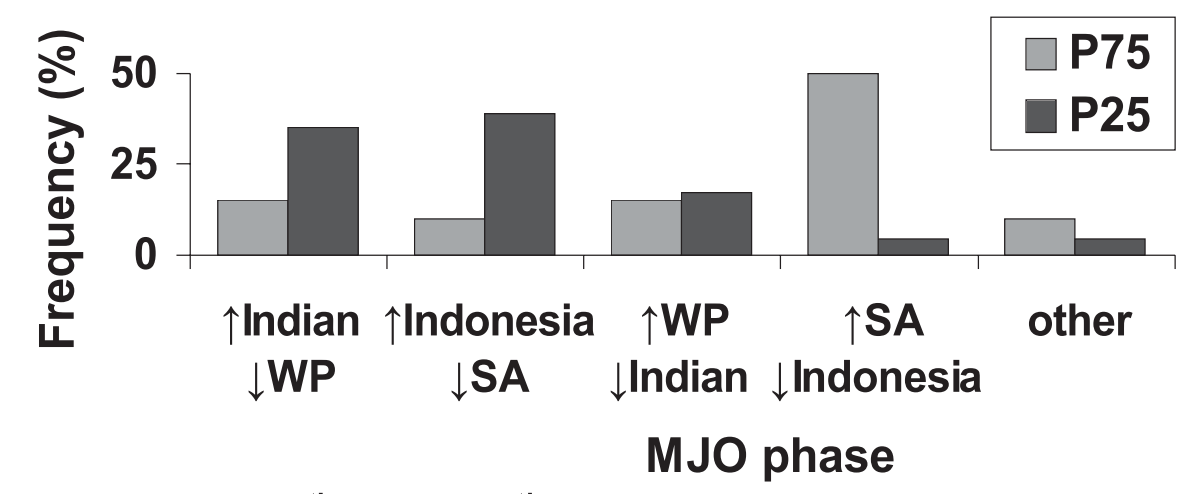

(b)

*total: 20 of $75^{\text {th }} ; 19$ of $25^{\text {th }}$

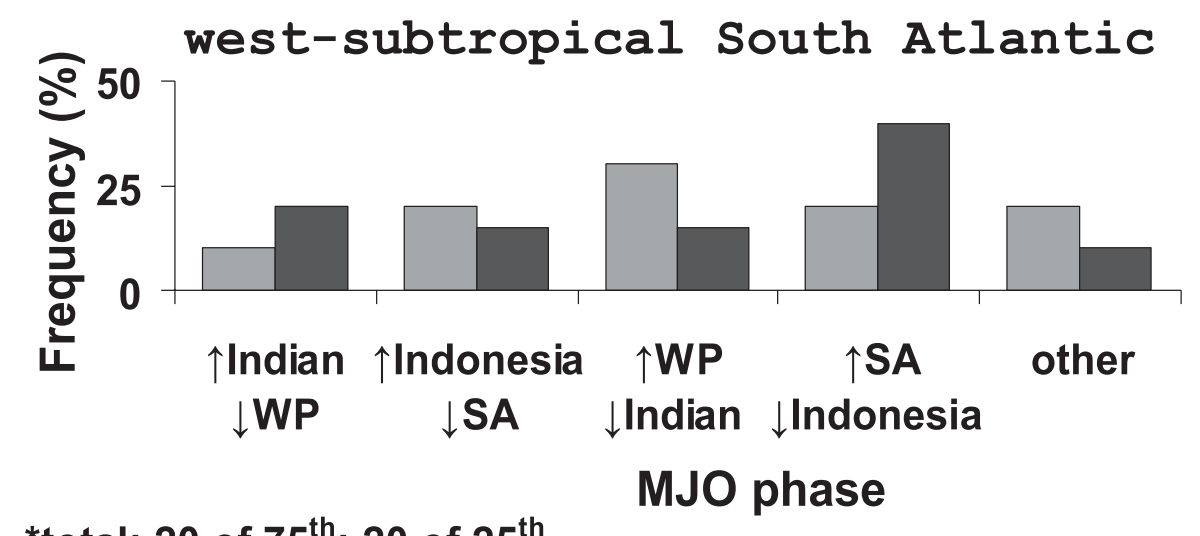

FIG. 11. Percentage of wet and dry intraseasonal extreme events observed in each MJO phase; (a) SEBr, (b) WAtl. Symbol " $"$ " (" $\downarrow$ ") indicates increase (decrease) of convection in that region according to Fig. 10. "Others" category indicates that the observation did not occur in any characteristic phase of the MJO. Total number of wet (P75) and dry (P25) events in each region is indicated at the bottom of each frame.

over northern South America, indicating the large contribution of moisture input from the equatorial Atlantic. These features appear along with $\bar{V}$ below the 25th percentile of the climatology east of the Andes. During dry intraseasonal events over SEBr (Fig. 12b), an en- hancement of the low low-level jet east of the Andes is observed, consistent with the results of Liebmann et al. (2004). The average magnitude of $\bar{V}$ is between the median and the upper quartile of the climatology for the region, except for a few grid points just east of the Andes

TABLE 1. The z-statistics for the difference in proportions of intraseasonal (20-90 days) extreme wet and dry events and MJO phases. Symbols and acronyms to identify distinct phases of the MJO follow the definitions of Fig. 10. Statistically significant differences at $5 \%$ $(10 \%)$ level are observed for $\mathrm{z}>1.64(\mathrm{z}>1.28)$.

\begin{tabular}{|c|c|c|c|c|c|c|c|}
\hline Event & Area & $\begin{array}{l}\uparrow \text { Indian } \downarrow \text { WP vs } \\
\uparrow \text { Indonesia } \downarrow \text { SA }\end{array}$ & $\begin{array}{c}\uparrow \text { Indian } \downarrow \text { WP vs } \\
\downarrow \text { Indian } \uparrow \mathrm{WP}\end{array}$ & $\begin{array}{c}\downarrow \text { Indonesia } \uparrow \text { SA vs } \\
\uparrow \text { Indian } \downarrow \text { WP }\end{array}$ & $\begin{array}{c}\uparrow \text { Indonesia } \downarrow \text { SA vs } \\
\downarrow \text { Indian } \uparrow \mathrm{WP}\end{array}$ & $\begin{array}{c}\uparrow \text { Indonesia } \downarrow \text { SA vs } \\
\downarrow \text { Indonesia } \uparrow \mathrm{SA}\end{array}$ & $\begin{array}{l}\downarrow \text { Indian } \uparrow W P \text { vs } \\
\downarrow \text { Indonesia } \uparrow S A\end{array}$ \\
\hline Wet & SEBr & 0.61 & 0.00 & 3.02 & 0.62 & 3.63 & 3.08 \\
\hline Dry & SEBr & 0.36 & 1.59 & 3.20 & 1.97 & 3.56 & 1.76 \\
\hline Wet & WAtl & 1.12 & 1.99 & 1.13 & 0.95 & 0.00 & 0.96 \\
\hline Dry & WAtl & 0.53 & 0.53 & 1.77 & 0.00 & 2.33 & 2.31 \\
\hline
\end{tabular}



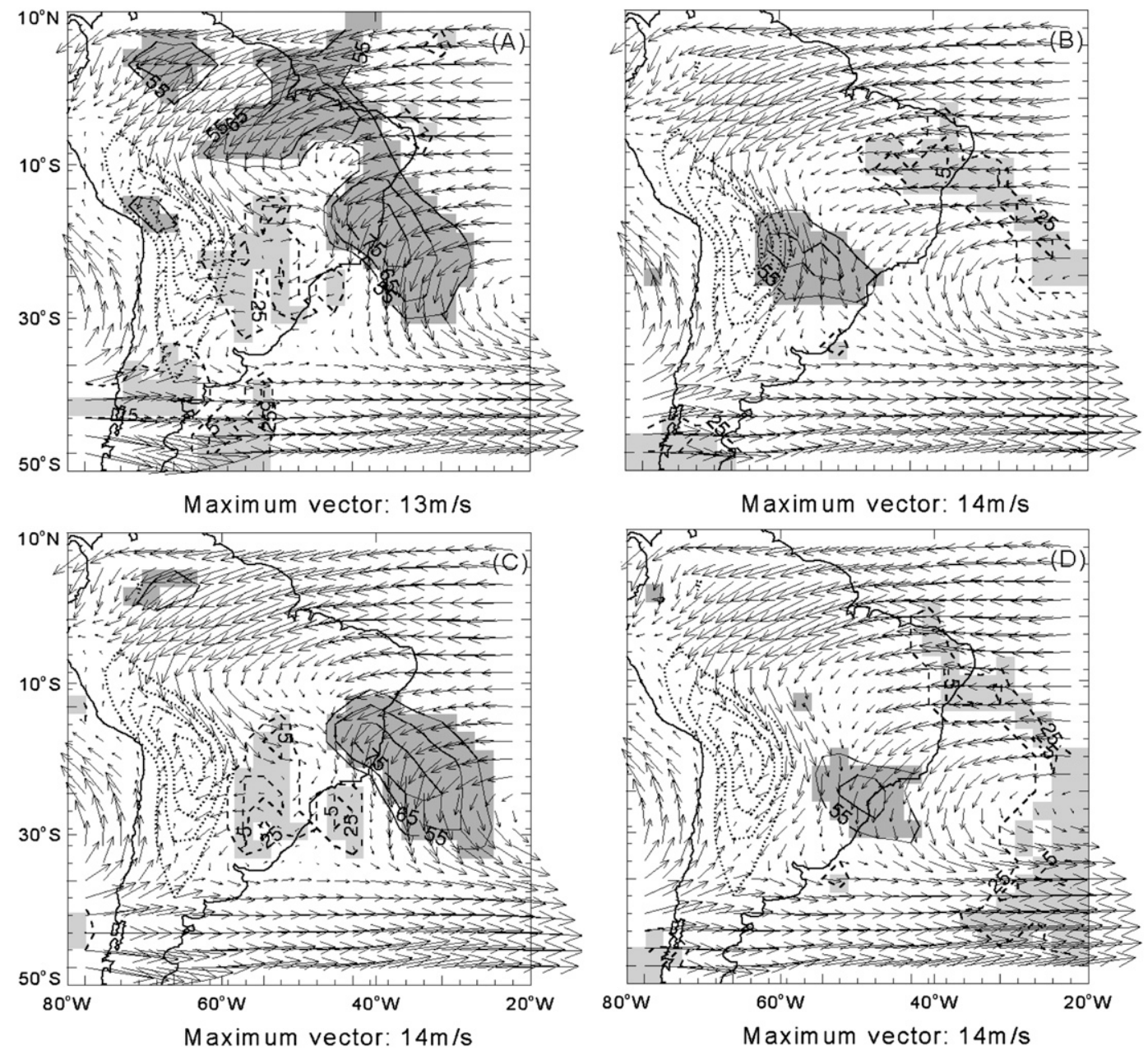

FIG. 12. The 850-hPa total wind $\left(\mathrm{m} \mathrm{s}^{-1}\right)$ during (a), (c) wet and (b), (d) dry extreme intraseasonal events over (a), (b) SEBr; (c), (d) WAtl. Solid lines indicate regions where the average magnitude of the meridional wind is above the 55th percentile of the climatology (lines are plotted every $10 \%$ interval). Dashed lines indicate regions where the magnitude of the meridional wind is below the 25 th percentile. This analysis is performed only where the intraseasonal anomalies of the meridional wind are statistically significant at $5 \%$ significance level (gray shades). Dotted contours show the terrain elevation beginning at $750 \mathrm{~m}$ with $500-\mathrm{m}$ intervals.

where the intensity is above the 75th percentile. These features are observed along with a decrease in magnitude of $\bar{V}$ over Northeastern Brazil extending toward the Atlantic Ocean and have not been documented before.

Wet extreme events over WAtl (Fig. 12c) are associated with the intensification of the northerly winds over eastern South America and over the Atlantic Ocean, north of WAtl. Unlike SEBr wet events (Fig. 12a), these winds have intensity above the upper quartile of the climatology only over the Atlantic and the southeastern coast of SA (Fig. 12c). Interesting enough, dry extreme events over WAtl (Fig. 12d) are not associated with an enhancement of $\bar{V}$ east of the Andes but over southeastern Brazil.

\section{Relationships between intraseasonal and low-frequency extreme events}

The occurrence of extreme events on low-frequency time scales certainly results from the interplay of phenomena occurring on several time scales. For example, a large number of storms or intense mesoscale systems during one season must increase the total seasonal precipitation. Analogously, more frequent cold fronts or long-lasting blocking conditions can also play a role in changing the seasonal climatology. The objective of the present section is to examine the importance of intraseasonal anomalies in contributing to extreme seasonal precipitation. 
TABLE 2. Distribution of intraseasonal (20-90 days) extreme events according to low-frequency anomalies during all seasons. Wet (dry) extreme events on low-frequency time scale are labeled as Wet $_{\mathrm{LF}}\left(\right.$ Dry $_{\mathrm{LF}}$ ), whereas wet (dry) extreme events on intraseasonal time scales are labeled as Wet IS $_{\text {(Dry }}$ ). Seasons not classified as dry or wet on low-frequency time scales are labeled as "neither." The $z$-statistics for the difference in proportions is also shown. Statistically significant differences at $5 \%(10 \%)$ level are observed for $-1.64>$ $z>1.64(-1.28>z>1.28)$. See text for more details.

\begin{tabular}{|c|c|c|c|c|}
\hline \multirow[b]{3}{*}{ Low-frequency extremes } & \multicolumn{4}{|c|}{ 20-90 days extreme events } \\
\hline & \multicolumn{2}{|c|}{$\mathrm{SEBr}$} & \multicolumn{2}{|c|}{ WAtl } \\
\hline & Wet $_{\text {IS }}$ & Dry $_{\text {IS }}$ & Wet $_{\text {IS }}$ & Dry $_{\text {IS }}$ \\
\hline Wet $_{L F}$ & $5(25 \%)$ & $8(42 \%)$ & $8(40 \%)$ & $8(40 \%)$ \\
\hline $\operatorname{Dry}_{L F}$ & $1(5 \%)$ & $6(32 \%)$ & $8(40 \%)$ & $4(20 \%)$ \\
\hline Neither & $14(70 \%)$ & $5(16 \%)$ & $4(20 \%)$ & $8(40 \%)$ \\
\hline $\begin{array}{l}\text { Total } \\
z \text {-statistics for the difference in proportions }\end{array}$ & 20 & 19 & 20 & 20 \\
\hline Wet $_{L F}-$ Dry $_{L F}$ & 0.97 & 0.38 & 0.00 & -0.75 \\
\hline Dry $_{L F}$-neither & -2.57 & 0.23 & 0.83 & -0.77 \\
\hline Neither-Wet ${ }_{L F}$ & 1.78 & -0.67 & -0.93 & 0.00 \\
\hline
\end{tabular}

Intraseasonal extreme anomalies are observed, on average, 1-2 times during one DJF season with persistence that varies from one to four pentads (Fig. 4) and variable intensity. A quantitative analysis about the frequency of wet and dry intraseasonal events during wet and dry low-frequency extreme events (labeled as $\mathrm{Wet}_{\mathrm{LF}}$ and Dry $\mathrm{LF}_{\mathrm{LF}}$, respectively) over SEBr and WAtl is shown in Table 2. Only 25\% (32\%) of the wet (dry) intraseasonal events occurred along with Wet $_{\mathrm{LF}}$ (Dry ${ }_{L F}$ ) events over SEBr. Nevertheless, the frequency of wet intraseasonal events that occurred in seasons with near-median low-frequency anomalies (labeled as "neither" in Table 2) is 70\%. The test of difference in proportions [Eq. (1)] indicates that more extreme intraseasonal wet events over SEBr have occurred during "neither" than during Wet LF $_{\mathrm{LF}}$ and Dry $\mathrm{LF}_{\mathrm{L}}$ seasons at 5\% significance level. No statistically significant differences were observed for the frequency of dry intraseasonal events over SEBr.

Over WAtl approximately the same proportion of wet intraseasonal events $(40 \%)$ occurred during Wet $_{\mathrm{LF}}$ and Dry $_{L F}$ seasons and the remaining $(20 \%)$ during "neither." About $40 \%$ of all dry intraseasonal events occurred during Wet $_{\mathrm{LF}}, 20 \%$ during Dry $_{\mathrm{LF}}$ and $40 \%$ during "neither." Differences are not statistically significant at $5 \%$ level.

Figure 13 illustrates the relationship between the frequency and intensity of intraseasonal anomalies and low-frequency anomalies during all seasons. Dark thick lines are the average in the area (SEBr and WAtl) of low-frequency anomalies during the season. Extreme wet and dry anomalies on low-frequency time scales are indicated in the figure by showing the year corresponding to December of that summer season. Gray lines represent the average intraseasonal anomalies observed in a given region during the season. Dashed lines indicate the 75th and 25th percentiles of the intraseasonal anomalies and are used as references to infer the occurrence of extreme anomalies on that time scale.

Figure 13 clearly indicates the complexity of the relationships between extreme wet or dry seasons and the intensity, duration, and frequency of the intraseasonal events in both regions. The occurrence of a strong wet intraseasonal event can be followed by long dry period (or vice versa) and the resulting contribution seems to depend on the timing of the events, intensity, and frequency. For instance, 1985 was a dry season over SEBr. Two intraseasonal events affected the area in that season, both causing wet and dry extreme anomalies. The wet anomalies do not seem to have been long or strong enough to compensate the dry anomalies. On the other hand, long-lasting events during the middle of the season or the occurrence of two or more strong events may have contributed substantially to the surplus of the seasonal precipitation in some seasons. Examples of the latter are observed in 1996 affecting SEBr and WAtl. Likewise, strong dry intraseasonal periods as observed in 1983 over SEBr seem to have contributed to the deficit of precipitation in that region. However, it is likely that the frequency and intensity of synoptic-scale systems such as cold fronts, with time scales shorter than 20 days, play a more efficient role in modulating extreme precipitation and dry conditions in the regions investigated here. The 1982 season over WAtl is one typical example that suggests an irrelevant importance of the intraseasonal activity for the seasonal anomalies. The enhancement of convection due to local processes not considered here is another aspect that can certainly contribute to the total seasonal precipitation. Moreover, given the interannual variability of the intraseasonal activity suggested in Fig. 13, there is an indication that 


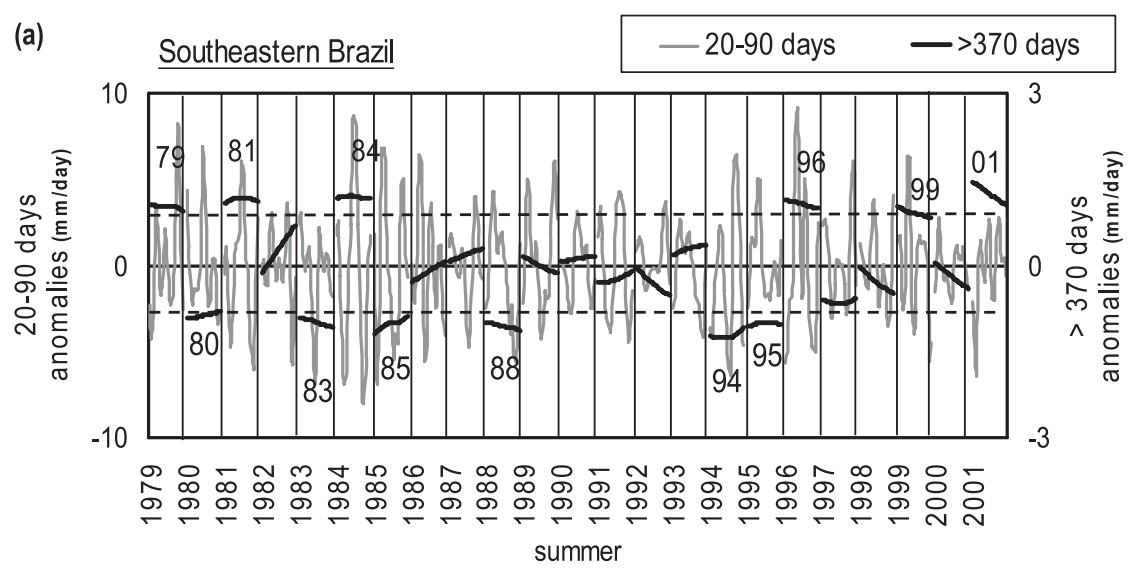

(b)

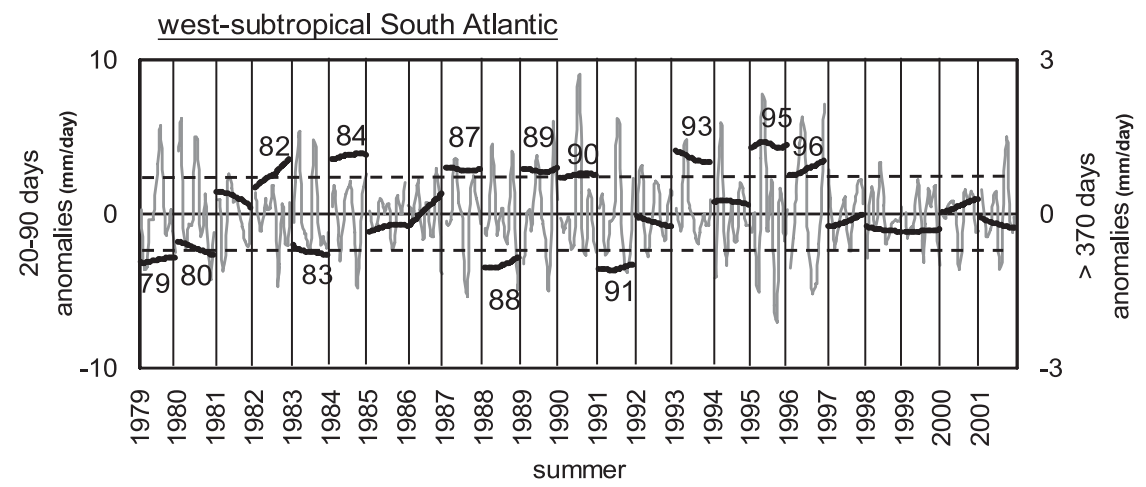

FIG. 13. Intraseasonal (20-90 days) anomalies (gray lines) averaged in each region during the occurrence of low-frequency (>370 days) extreme events; (a) SEBr, (b) WAtl. Dashed lines show the upper and lower quartile of the intraseasonal anomalies to indicate the occurrence of extreme events on that time scale. The average low-frequency anomalies in grid points that observed extreme events in each region are indicated by dark lines. Years corresponding to the extreme events are shown inside the figure and are not the same for all regions.

the dynamics responsible for extreme wet or dry seasons do not play a substantial role in modulating intraseasonal activity over southeastern South America.

\section{Conclusions}

The present observational study explored some dynamical features associated with the occurrence of extreme wet and dry events on intraseasonal (20-90 days) and low-frequency ( $>370$ days) time scales over southeastern South America and subtropical western Atlantic during the austral summer. One unique aspect of this study is the additional focus on the western subtropical Atlantic where the oceanic activity of the SACZ has been observed. Moreover, we addressed relationships between intraseasonal and low-frequency extreme anomalies that have not been explored before.

Dominant dynamical mechanisms during extreme events on low-frequency time scales seem quite dependent on the regions we are focusing on. Extreme dry and wet conditions have no clear relationships with ENSO over SEBr and WAtl. Nevertheless, we found indication that the enhancement of convection over SEBr is related to suppression of convection over the equatorial western Pacific $\left(\sim 180^{\circ}-120^{\circ} \mathrm{W}\right)$ and enhancement over the Maritime Continent. In contrast, the enhancement of convection over the SPCZ and suppression over the equatorial Pacific is related to dry conditions on low-frequency time scales over SEBr. In addition, the reversal of the South Atlantic dipole seems to have a more effective relationship with extreme events over SEBr and WAtl than the SST in the equatorial Pacific.

Composites of upper-level circulation indicate that wet (dry) extreme events on low-frequency time scales are systematically related to westerly (easterly) anomalies. A broad region with easterly anomalies and largely zonal features in the Southern Hemisphere is observed during dry events over SEBr. Atmospheric mechanisms driving extreme anomalies over WAtl seem to be distinct from those that cause extreme events over SEBr, 
emphasizing the importance of the decoupling between the oceanic and continental precipitation patterns over the SACZ region. Moreover, there is no clear evidence of a seesaw of extreme events between $\mathrm{SEBr}$ and south Brazil on low-frequency time scales. Near-surface circulation clearly indicates the importance of the dominance of westerly (easterly) wind anomaly regimes for wet (dry) seasons over SEBr. Over WAtl, the occurrence of extreme wet (dry) seasons depends largely on the anomalous equatorward (poleward) flows toward the subtropical Atlantic Ocean.

On intraseasonal time scales, a large correspondence among extreme events in all regions is consistent with the propagation of extratropical wave trains, as shown in several previous studies referred to in this paper. Here we identified the relationships between the frequency of events and phases of the MJO. It is important to emphasize that not all intraseasonal activity studied in this paper was clearly and unequivocally connected to the MJO extratropical Rossby response (e.g., Ferranti et al. 1990). Nevertheless, we showed that distinct phases of propagation of the MJO have different impacts on the frequency of extreme wet and dry events over these regions. Another result complementary to the Liebmann et al. (2004) study indicated that extreme events on intraseasonal time scales over SEBr and WAtl are related to the occurrence of meridional winds above the 75th percentile over eastern tropical Brazil extending toward the ocean. The combination of these results suggests that the tropical variability in circulation observed in this region is likely modulated by the MJO Kelvin response in the tropics.

Associations between intraseasonal variability and extreme wet and dry events on low-frequency time scales indicate a very complex pattern of covariability. The number and intensity of intraseasonal events may influence the total precipitation of the season depending on their timing. Moreover, other time scales not investigated in this study such as the synoptic $(<10$ days $)$ and mesoscale $(<1$ day) may significantly contribute to the total precipitation during the summer season and need to be considered to properly address the variability of extreme events on low-frequency time scales.

Acknowledgments. The authors thank Dave Allured for gridded-precipitation data processing. Rainfall station data was provided by DAEE and ANEEL and GPCP by NOAA. The NCEP-NCAR reanalysis and OLR data were provided by NOAA/ESRL Physical Sciences Division. The authors greatly acknowledge the financial support of the following agencies: M. N. Muza CNPq (140280/2006-5); L.M.V. Carvalho FAPESP (02/ 09289-9) and CNPq (302203/02-8; 482447/07-9); L.
Carvalho, C. Jones, and B. Liebmann NOAA CPPA program (NA07OAR4310211); L Carvalho and C. Jones NOAA (NA05OAR4311129).

\section{REFERENCES}

Carvalho, L. M. V., C. Jones, and B. Liebmann, 2002a: Extreme precipitation events in southeastern South America and largescale convective patterns in the South Atlantic convergence zone. J. Climate, 15, 2377-2394.

$\longrightarrow,-$, and M. A. F. Silva Dias, 2002b: Intraseasonal largescale circulations and mesoscale convective activity in tropical South America during the TRMM-LBA campaign. J. Geophys. Res., 107, 8042, doi:10.1029/2001JD000745.

_ D. Lavallée, and C. Jones, 2002c: Multifractal properties of evolving convective systems over tropical South America. Geophys. Res. Lett., 29, 1743, doi:10.1029/2001GL014276.

_ C. C. Jones, and B. Liebman, 2004: The South Atlantic convergence zone: Intensity, form, persistence, relationships with intraseasonal to interannual activity and extreme rainfall. $J$. Climate, 17, 88-108.

,-- , and T. Ambrizzi, 2005: Opposite phases of the Antarctic Oscillation and relationships with intraseasonal to interannual activity in the tropics during the austral summer. $J$. Climate, 18, 702-718.

Casarin, D. P., and V. E. Kousky, 1986: Anomalias de precipitação no sul do Brasil e variações na circulação atmosférica. Res. Bras. Meteor., 1, 83-90.

Ferranti, L., T. N. Palmer, F. Monteni, and E. Klinker, 1990: Tropical-extratropical interaction associated with the 30-60day oscillation and its impact on medium range and extended range prediction. J. Atmos. Sci., 47, 2177-2199.

Figueroa, S. N., P. Satyamyrty, and P. L. Silva-Dias, 1995: Simulations of the summer circulation over the South American region with an ETA coordinate model. J. Atmos. Sci., 52, 1573-1584.

Gan, M. A., V. E. Kousky, and C. F. Ropelewski, 2004: The South America monsoon circulation and its relationship to rainfall over west-central Brazil. J. Climate, 17, 47-66.

Grimm, A. M., 2003: The El Niño impact on the summer monsoon in Brazil: Regional processes versus remote influences. $J$. Climate, 16, 263-280.

_ _ and P. L. Silva Dias, 1995: Analysis of tropical-extratropical interactions with influence functions of a barotropic model. $J$. Atmos. Sci., 52, 3538-3555.

Herdies, D. L., A. da Silva, A. Silva Dias, and R. Nieto-Ferrari, 2002: Moisture budget of the bimodal pattern of the summer circulation over South America: Large-scale biosphereatmosphere experiment in Amazonia (LBA). J. Geophys. Res., 107, 8075, doi:10.1029/2001JD000997.

Jones, C., and L. M. V. Carvalho, 2002: Active and break phases in the South American monsoon system. J. Climate, 15, 905-914.

— D. E. Waliser, and E. C. Gautier, 1998: The influence of the Madden-Julian oscillation on ocean surface heat fluxes and sea surface temperature. J. Climate, 11, 1057-1072.

,,-- K. M. Lau, and W. Stern, 2004: Global occurrences of extreme precipitation events and the Madden-Julian oscillation: Observations and predictability. J. Climate, 17, 4575-4589.

Kalnay, E., and Coauthors, 1996: The NCEP/NCAR Reanalysis 40-Year Project. Bull. Amer. Meteor. Soc., 77, 437-471.

Karoly, D. J., 1989: Southern Hemisphere circulation features associated with El Niño-Southern Oscillation events. J. Climate, 2, 1239-1252. 
Kodama, Y. M., 1992: Large-scale common features of subtropical precipitation zones (the Baiu frontal zone, the SPCZ, and the SACZ). Part I: Characteristics of subtropical frontal zones. $J$. Meteor. Soc. Japan, 70, 813-835.

_ 1993: Large-scale common features of subtropical precipitation zones (the Baiu frontal zone, the SPCZ, and the SACZ). Part II: Conditions of the circulation and tropical convection over the Pacific. J. Meteor. Soc. Japan, 71, 581-610.

Kousky, V. E., and M. T. Kayano, 1994: Principal modes of outgoing longwave radiation and $250-\mathrm{mb}$ circulation for the South American sector. J. Climate, 7, 1131-1143.

Lenters, J. D., and K. H. Cook, 1999: Summertime precipitation variability over South America: Role of the large-scale circulation. Mon. Wea. Rev., 127, 409-431.

Liebmann, B., and C. Smith, 1996: Description of a complete (interpolated) outgoing longwave radiation dataset. Bull. Amer. Meteor. Soc., 77, 1275-1277.

— , and J. A. Marengo, 2001: Interannual variability of the rainy season and rainfall in the Brazilian Amazon basin. J. Climate, 14, 4308-4318.

— America. Bull. Amer. Meteor. Soc., 86, 1567-1570.

_ , G. N. Kiladis, J. A. Marengo, T. Ambrizzi, and J. D. Glick, 1999: Submonthly convective variability over South America and the South Atlantic convergence zone. J. Climate, 12 , 1877-1891.

_ C. Jones, and L. M. V. Carvalho, 2001: Interannual variability of extreme precipitation events in the state of São Paulo, Brazil. J. Climate, 14, 208-218.

- , G. N. Kiladis, C. S. Vera, A. C. Saulo, and L. M. V. Carvalho, 2004: Subseasonal variations of rainfall in South America in the vicinity of the low-level jet east of the Andes and comparison to those in the South Atlantic convergence zone. $J$. Climate, 17, 3829-3842.
Marengo, J. A., B. Liebmann, V. E. Kousky, N. P. Filizola, and I. C. Wainer, 2001: Onset and end of the rainy season in the Brazilian Amazon basin. J. Climate, 14, 833-852.

Mo, K. C., and J. Nogués-Paegle, 2001: The Pacific-South American modes and their downstream effects. Int. J. Climatol., 21, 1211-1229.

Nogués-Paegle, J., and K. C. Mo, 1997: Alternating wet and dry conditions over South America during summer. Mon. Wea. Rev., 125, 279-291.

_ L. A. Byerle, and K. C. Mo, 2000: Intraseasonal modulation of South American summer precipitation. Mon. Wea. Rev., 128, 837-850.

Robertson, A. W., and C. R. Mechoso, 2000: Interannual and interdecadal variability of the South Atlantic convergence zone. Mon. Wea. Rev., 128, 2947-2957.

Ropelewski, C. F., and M. S. Halpert, 1987: Global and regional scale precipitation patterns associated with the El Niño/ Southern Oscillation. Mon. Wea. Rev., 115, 1606-1626.

Silva, A. E., and L. M. V. Carvalho, 2007: Large-scale index for South America monsoon (LISAM). Atmos. Sci. Lett., 8, 51-57.

Spiegel, M. R., J. J. Schiller, and A. L. Srinivasan, 2000: Schaum's Outline of Probability and Statistics. McGraw-Hill, 220 pp.

Vera, C., and Coauthors, 2006: Toward a unified view of the American monsoon systems. J. Climate, 19, 4977-5000.

Weickmann, K. M., G. R. Lussky, and J. E. Kutzbach, 1985: Intraseasonal (30-60 day) fluctuation of outgoing longwave radiation and 250-mb streamfunction during northern winter. Mon. Wea. Rev., 113, 941-961.

Wilks, D. S., 1995: Statistical Methods in the Atmospheric Sciences. Academic Press, 467 pp.

Xie, P., and Coauthors, 2003: GPCP pentad precipitation analyses: An experimental dataset based on gauge observations and satellite estimates. J. Climate, 16, 2197-2214.

Zhou, J., and K. M. Lau, 1998: Does a monsoon climate exist over South America? J. Climate, 11, 1020-1040. 